Journal for ImmunoTherapy of Cancer

\section{Endogenous HLA-DQ8 $\alpha \beta$ programs superantigens (SEG/SEI) to silence toxicity and unleash a tumoricidal network with long-term melanoma survival}

To cite: Knopick P, Terman D, Riha N, et al. Endogenous HLADQ8 $\alpha \beta$ programs superantigens (SEG/SEI) to silence toxicity and unleash a tumoricidal network with long-term melanoma survival. Journal for ImmunoTherapy of Cancer 2020;8:e001493. doi:10.1136/ jitc-2020-001493

- Additional material is published online only. To view please visit the journal online (http://dx.doi.org/10.1136/jitc2020-001493).

DT and DB contributed equally.

DT and DB are joint senior authors.

Accepted 10 September 2020

Check for updates

(C) Author(s) (or their employer(s)) 2020. Re-use permitted under CC BY-NC. No commercial re-use. See rights and permissions. Published by BMJ.

${ }^{1}$ Biomedical Sciences, Universtiy of North Dakota School of Medicine, Grand Forks, North Dakota, USA

${ }^{2}$ University of Lyon, Lyon, Auvergne-Rhône-Alpes, France ${ }^{3}$ University of Lyon 1 University Institute of Tecnology Lyon 1, Villeurbanne, Auvergne-RhôneAlpes, France

${ }^{4}$ Aldevron LLC, Fargo, North Dakota, USA

Correspondence to

Dr David Terman;

dst@sbcglobal.net

\section{ABSTRACT}

Background As the most powerful T cell agonists known, superantigens (SAgs) have enormous potential for cancer immunotherapy. Their development has languished due to high incidence $(60 \%-80 \%)$ of seroreactive neutralizing antibodies in humans and tumor necrosis factor- $\alpha$ (TNF $\alpha$ )-mediated cardiopulmonary toxicity. Such toxicity has narrowed their therapeutic index while neutralizing antibodies have nullified their therapeutic effects. Methods Female HLA-DQ8 (DQA*0301/DQB*0302) tg mice expressing the human major histocompatibility complex II (MHCII) HLA-DQ8 allele on a high proportion of PBL, spleen and lymph node cells were used. In the established tumor model, staphylococcal enterotoxin $\mathrm{G}$ and staphylococcal enterotoxin I (SEG/ SEI) $(50 \mu \mathrm{g}$ each) were injected on days 6 and 9 following tumor inoculation. Lymphoid, myeloid cells and tumor cell digests from tumor tissue were assayed using flow cytometry or quantitated using a cytometric bead array. Tumor density, necrotic and viable areas were quantitated using the ImageJ software. Results In a discovery-driven effort to address these problems we introduce a heretofore unrecognized binary complex comprizing SEG/SEl SAgs linked to the endogenous human MHCII HLA-DQ8 allele in humanized mice. By contrast to staphylococcal enterotoxin $A$ (SEA) and staphylococcal enterotoxin B (SEB) deployed previously in clinical trials, SEG and SEl does not exhibit neutralizing antibodies in humans or TNF $\alpha$-mediated toxicity in humanized HLA-DQ8 mice. In the latter model wherein SAg behavior is known to be 'human-like', SEG/ SEl induced a powerful tumoricidal response and longterm survival against established melanoma in $82 \%$ of mice. Other SAgs deployed in the same model displayed toxic shock. Initially, HLA-DQ8 mediated melanoma antigen priming, after which SEG/SEl unleashed a broad CD4+ and CD8+ antitumor network marked by expansion of melanoma reactive T cells and interferon- $\gamma$ (IFNy) in the tumor microenvironment (TME). SEG/SEl further initiated chemotactic recruitment of tumor reactive $T$ cells to the TME converting the tumor from 'cold' to a 'hot'. Long-term survivors displayed remarkable resistance to parental tumor rechallenge along with the appearance of tumor specific memory and tumor reactive T memory cells.
Conclusions Collectively, these findings show for the first time that the SEG/SEI-(HLA-DQ8) empowers priming, expansion and recruitment of a population of tumor reactive $T$ cells culminating in tumor specific memory and long-term survival devoid of toxicity. These properties distinguish SEG/SEl from other SAgs used previously in human tumor immunotherapy. Consolidation of these principles within the SEG/SEI-(HLA-DQ8) complex constitutes a conceptually new therapeutic weapon with compelling translational potential.

\section{INTRODUCTION}

While immunotherapy of cancer has achieved several notable successes using both antigen specific and antigen non-specific approaches, of paramount concern to investigators is that a substantial fraction of patients fail to respond to these measures. ${ }^{1-3}$ This has fueled a universal search for conceptually new tools and strategies to eradicate solid tumors. To this end, we examine bacterial superantigens (SAgs) the most powerful $\mathrm{T}$ cell agonists known with intrinsic $\mathrm{T}$ cell receptor (TCR) and costimulatory activating properties in an effort to harness their vast hidden potential for cancer treatment.

The enterotoxins of Staphylococcus aureus (SEs) comprise a group of globular proteins with diverse sequences capable of activating up to $20 \%$ of the $\mathrm{T}$ cell repertoire. ${ }^{4}$ These molecules, known as SAgs, further form a bridge between the $\alpha$ - and/or $\beta$-chains of major histocompatibility complex II (MHC II) molecules and the variable component of the $\beta$-chain of TCRs leading to $\mathrm{T}$ cell activation. $^{5}{ }^{6}$ This canonical MHCII-SAg-TCR model has been recently revised following the revelation that $\mathrm{SAgs}$ possess intrinsic ligands that engage homodimeric sites on B7-2 and CD28 costimulatory molecules that regulate 
CD4+ Tcell cytokine output. ${ }^{7-9}$ While SAgs induce nonspecific, polyclonal expansion of CD4+ and CD8+T cells along with cytokines such as interferon- $\gamma$ (IFN $\gamma)$ and tumor necrosis factor- $\alpha$ (TNF $\alpha)$ they also activate recall $\mathrm{T}$ cell responses against viral, bacterial, autoimmune and tumor targets. ${ }^{10-13}$ Despite these shared properties, individual SAgs exhibit broad diversity in the strength of their $\mathrm{T}$ effector cell, $\mathrm{T}$ regulatory cell (Tregs) responses and cytokine output largely due to their differential topology and affinity for MHCII haplotypes and TCR. ${ }^{14-17}$

With respect to cancer treatment, canonical SAgs such as SEA and SEBalone or fused to tumor targeted antibodies have demonstrated antitumor effects in animal models. ${ }^{18} 19$ Their application to human cancer, however, has been hampered by hemodynamic toxicity and the presence of pre-existent seroreactive neutralizing antibodies. ${ }^{20}{ }^{21}$ In human trials, these antibodies nullified the therapeutic effect of SAgs, contributed to their toxicity, and narrowed the number of human cancer patients eligible for treatment. ${ }^{20}{ }^{22}$ Indeed, tumor remissions in response to canonical SAgs occurred predominantly in patients with minimal to absent levels of such neutralizing antibodies. ${ }^{21}$ In addition, the T cell-mediated tumor cytotoxic effects generated by wild type SAgs in humans have been invariably accompanied by TNF $\alpha$-mediated hemodynamic toxicity. ${ }^{20}$ These findings spawned a quest to identify SAgs that exhibit minimal levels of neutralizing antibodies while conserving $\mathrm{T}$ cell effector and silencing TNF $\alpha$ activity. Our search led us to the staphylococcal enterotoxin growth cluster (egcSEs) of SAgs originally described by Lina and colleagues. ${ }^{23}$ This grouping is present in $80 \%$ or Staphyloococcus aureus isolates and consists of five functional enterotoxins situated in an operon outside of the core-genome.$^{24}{ }^{25}$ Unlike canonical SEA, sepsis associated with these SEs was attended by a significantly lower incidence of toxic shock. ${ }^{26} \mathrm{~A}$ functional assessment of individual egcSEs showed that while both SEG and SEI induced potent T cell activation, SEG produced the lowest levels of TNFo and SEI the highest levels of IFN- $\gamma .{ }^{14}$ SEG and SEI were further shown to exhibit low levels of pre-existing neutralizing antibodies in human sera largely ascribed to weak transcription and suboptimal toxin secretion by the parental Staphylococcus aureus. ${ }^{27} 28$ Their subdued toxicity coupled with minimal levels of neutralizing antibodies in human sera suggested that these agents might work together to produce a more favorable therapeutic index against human cancer than previously deployed SEs.

The quality and strength of SAg-induced T effector cell and cytokine responses are critically reliant on their functional interaction with endogenous MHCII. We thereby commenced a search for human MHC class II allele that could preserve SEG/SEI T effector function in vivo while silencing the disabling effects of toxicity-inducing TNF $\alpha$. Kotb et al underscored the clinical relevance of SAg specificity for human MHCII alleles in governing the severity of toxicity induced by streptococcal pyrogenic exotoxin (SPEA) 1 in streptococcal sepsis. ${ }^{16} 17$ To examine the effect of MHCII alleles on SEG/SEI behavior, we turned to transgenic murine models that express human MHC class II in the absence of murine MHCII on a large percentage of myeloid cells. ${ }^{29}$ Because human MHCII allotypes are more efficient at $\mathrm{SAg}$ presentation than their murine MHCII counterparts, these humanized models have been preferred by investigators to examine human-like $\mathrm{T}$ cell and cytokine responses against canonical SAgs such as SpeA and SEB. ${ }^{30}$ For these studies, we selected the MHCII transgenic model expressing the HLA-DQ8 allele (DQA*03:01, DQB*03:02) because of its broad expression in humans and structural features that include highly polymorphic $\alpha$-chain and $\beta$-chain variants capable of engaging SAgs and a broad repertoire of peptides. ${ }^{31-33}$ Indeed, a group of human and murine melanoma neopeptides that binds selectively to MHCII and/or HLA-DQ alleles and activates CD4+ T cells was recently unearthed via high throughput epitope mining. ${ }^{34-37}$ To our knowledge, humanized MHCII transgenic mice including the humanized HLA-DQ8 model have not been previously exploited to examine the effect of SAgs and/or tumor neopeptides in antitumor therapy.

Our working hypothesis was that SEG/SEI's unique properties deployed in humanized HLA-DQ8 tg mice could enable an antitumor response against established melanoma without undue toxicity. Remarkably, the humanized model unveiled the nature and scale of the tumoricidal response and long-term challenge-resistant survival induced by these SAgs. The tumoricidal response preserved $\mathrm{T}$ cell-mediated tumor killing while negating TNF $\alpha$-induced toxicity. SEG/SEI in this model further unleashed a broad CD4+ and CD8+Tcell mediated anti-tumor network marked by tumor antigen priming, chemotactic mobilization and recruitment of tumor reactive $\mathrm{T}$ cells culminating in the appearance of tumor specific memory.

\section{RESULTS}

\section{SEG/SEI induce robust T cell proliferation and production of $\mathrm{T}$ cell effector molecules along with diminished Treg differentiation in splenocytes from humanized MHCII mice}

Although a fundamental feature of SAgs is the ability to induce robust $\mathrm{T}$ cell mitogenesis, individual SAgs often exhibit differential proliferative strength. ${ }^{21} 22{ }^{26}$ In initial studies, we therefore compared the mitogenic activity of SEG, SEI, SEG/SEI with canonical SAgs SEB and SEA using naïve splenocytes from MHCII HLA-DQ8 humanized mice and C57BL/6 mice (MHCII I-A ${ }_{\alpha}{ }^{\mathrm{b}} \mathrm{I}-\mathrm{A}_{\beta}{ }^{\mathrm{b}}$ ). In 1 both strains, SEG, SEI, SEG/SEI, induced proliferation in CD4+ and CD $8+T$ cells comparable to that of canonical SEB and SEA (figure 1A,B). This finding affirmed the potent $\mathrm{T}$ cell mitogenic ability of SEG, SEI and SEG/SEI. Notably, T cell mitogenesis induced by all SEs in splenocytes from HLADQ8 humanized mice was more potent relative to that of C57BL/6 splenocytes (figure 1A,B). The subdued proliferative response of $\mathrm{C} 57 \mathrm{BL} / 6$ mice has been attributed to 
A
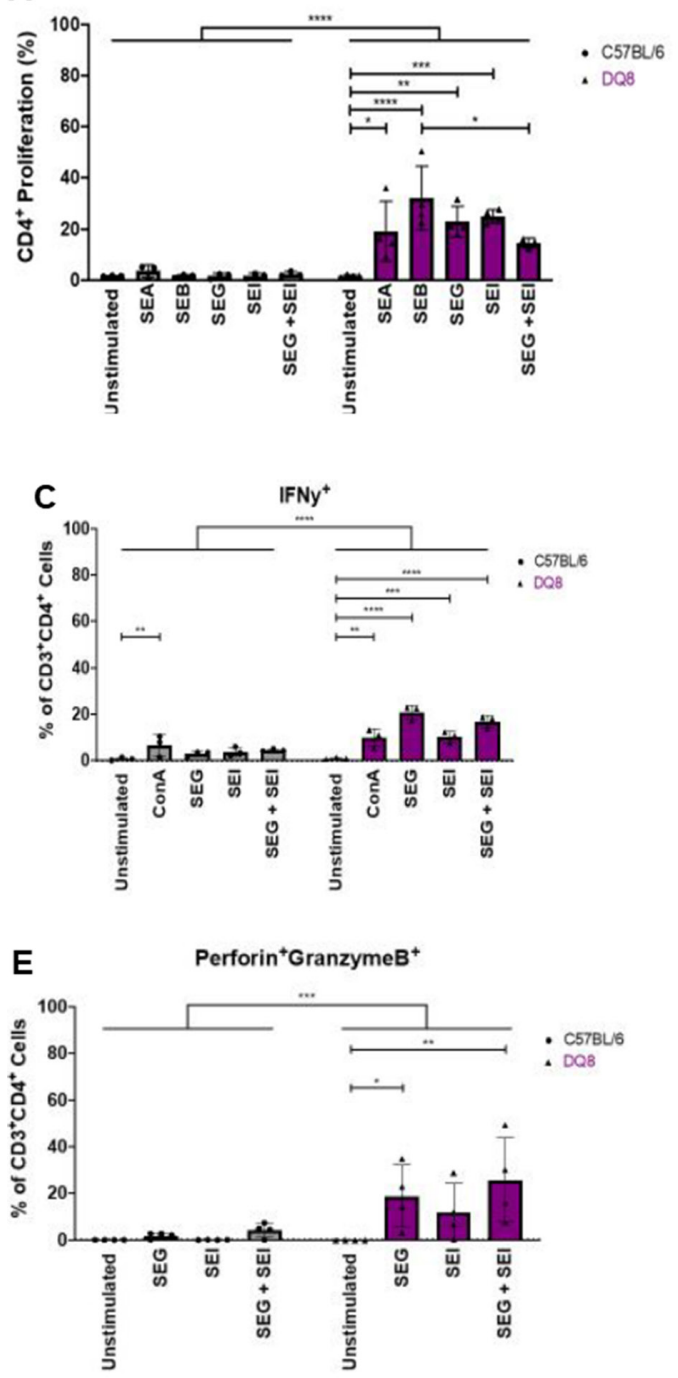

B
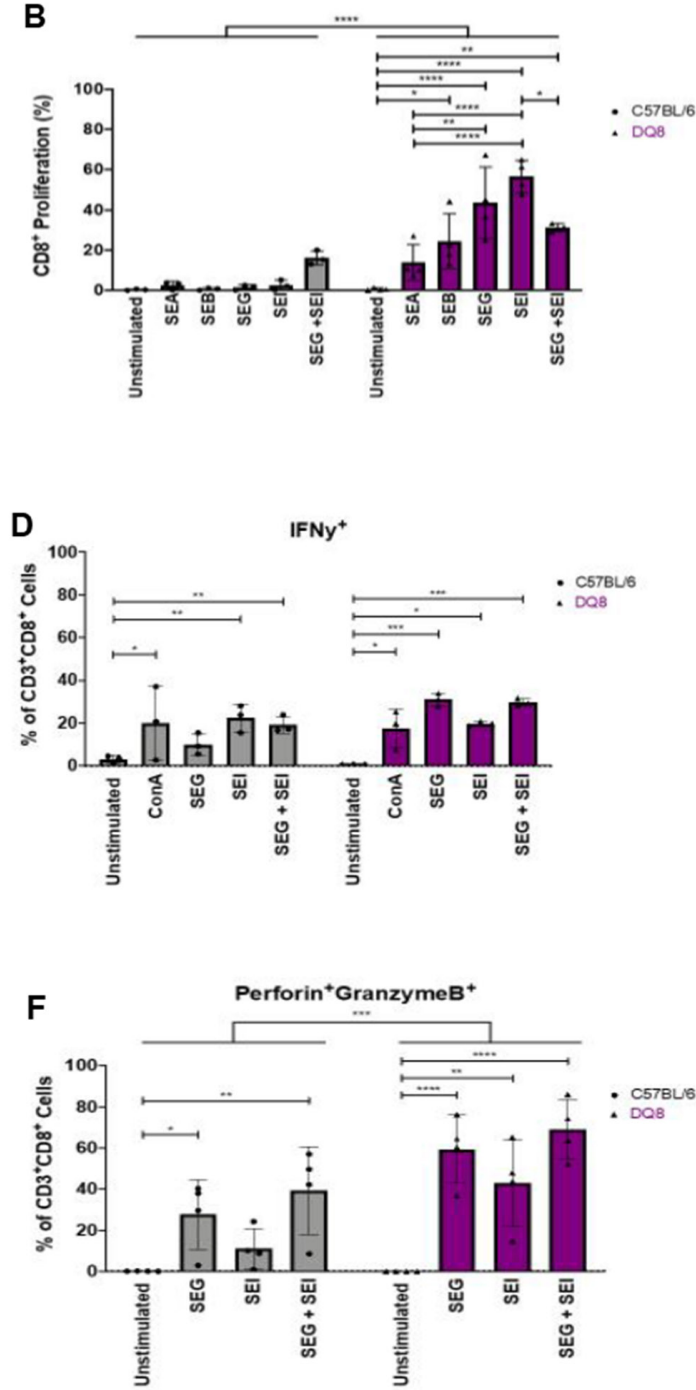

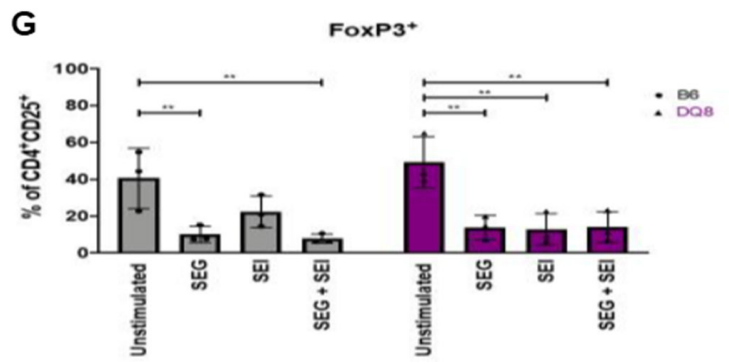

Figure 1 Evaluation of mitogenic strength, T cell effector and Treg differentiation in response to SEG, SEl and SEG/SEl in vitro. CD4+ and CD8+ splenocytes from HLA-DQ8 tg, and C57BL/6 mice were incubated with SEA, SEB, SEG, SEI, $(1 \mu \mathrm{g} / \mathrm{mL})$ and SEG/SEI ( $0.5 \mu \mathrm{g} / \mathrm{of}$ each) for 72 hours and assayed for proliferation (A, B). CD4+ and CD8+T cells from HLA-DQ8 TG, and C57BL/6 mice were incubated with SEG, SEl $(1 \mathrm{ug} / \mathrm{mL})$ or SEG/SEI $(0.5 \mu \mathrm{g} / \mathrm{mL}$ of each) for 72 hours and assayed for IFN $\gamma(C, D)$ or granzyme and perforin (E, F). CD4 +T cells from HLA-DQ8 TG, and C57BL/6 mice were incubated with SEG, SEl, $(1 \mu \mathrm{g} / \mathrm{mL})$ or SEG/SEl $(0.5 \mu \mathrm{g} / \mathrm{mL}$ of each) for 72 hours and FOXP3 expression was quantified (G). Data expressed as mean \pm SD. ANOVA with Tukey post test, $n=3-5 .{ }^{*} \mathrm{P}<0.05,{ }^{* *} \mathrm{p}<0.01,{ }^{* \star \star} \mathrm{p}<0.001,{ }^{* \star \star *} \mathrm{p}<0.001$.

reduced binding affinities of SAg to murine MHCII alleles. ${ }^{38}$ Next, we evaluated the ability of SEG, SEG and SEG/SEI to activate key $\mathrm{T}$ cell effector molecules, IFN $\gamma$ and perforingranzyme-B, in murine CD4 +andCD8+T cells. SEG, SEI and SEG/SEI stimulated increased levels of IFN $\gamma$ in CD4 +splenocytes from HLA-DQ8 tg and C57BL/6 mice but comparable levels of IFN $\gamma$ in CD8+ cells from both strains (figure 1C,D). CD4+ and CD8+T splenocytes from HLADQ8 tg mice showed significantly higher levels of perforingranzyme-B levels relative to splenocytes from C57BL/6 
mice (figure 1E,F). We next evaluated the capacity of SEG/SEI to induce differentiation of CD4 +CD25+Foxp3+ (Tregs) in T cells from HLA-DQ8 tg and C57BL/6 mice. In both strains, SEG, SEI and SEG/SEI induced significant reductions of the Treg population relative to the untreated controls (figure 1G). Collectively, these findings indicate that SEG, SEI and SEG/SEI presented by HLA-DQ8 splenocytes from humanized HLA-DQ8 tg mice possess robust $\mathrm{T}$ cell proliferative function comparable to that of canonical SEA and SEB. SEG, SEI. SEG/SEI further demonstrate an ability to stimulate key $\mathrm{T}$ effector cell molecules, IFN $\gamma$ and perforin-granzyme-B while diminishing the Treg population. The reduced proliferation and $\mathrm{T}$ effector response to SEG/SEI noted in C57BL/ 6 splenocytes expressing murine MHCII relative to splenocytes from HLA-DQ8 tg mice displaying human MHCII accords with previous reports. ${ }^{38}$
SEG/SEI-treated HLA-DQ8 tg mice display long-term survival of established B16-F10 melanoma and resistance to tumor rechallenge

In preliminary studies, we examined the genetic compatibility of HLA-DQ8 tg and C57BL/6 mice. As expected from their shared genetic background ${ }^{39}$ mitomycin treated C57BL/6 splenocytes failed to stimulate HLADQ8 cells in mixed lymphocyte culture (online supplemental figure 1A). Predictably, the B16-F10 melanoma indigenous to the C57BL/6 mice was lethal in both strains 20 days after receiving a tumorigenic dose of B16F10 melanoma cells (figure 2A,B). HLA-DQ8 tg mice y were not immunologically impaired since they eradicated the genetically unrelated $4 \mathrm{~T} 1$ carcinoma of $\mathrm{Balb} / \mathrm{C}$ origin (online supplemental figure 1B). We also established that within 6 days after injection of B16-F10 melanoma
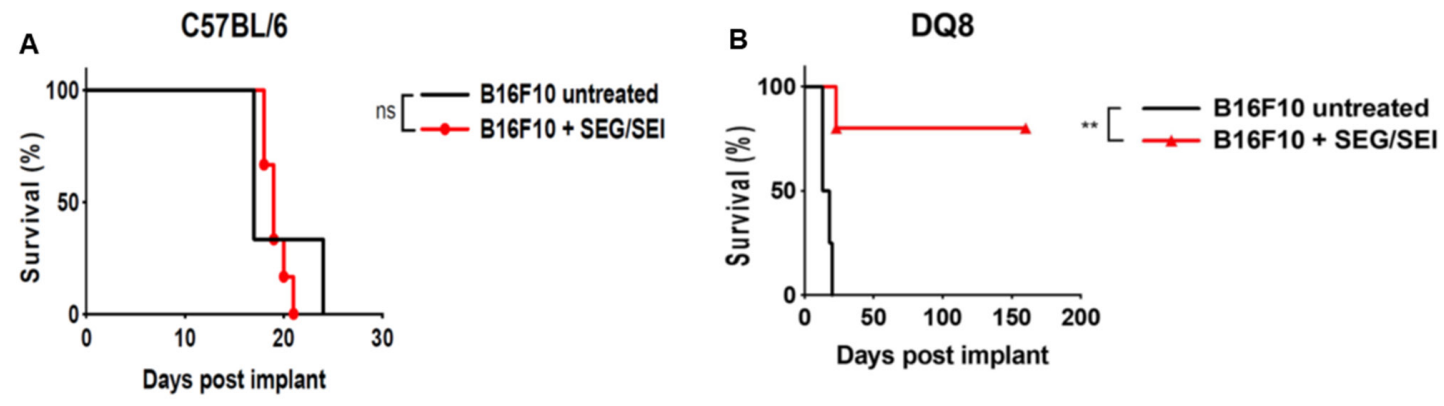

C

B16 Rechallenge
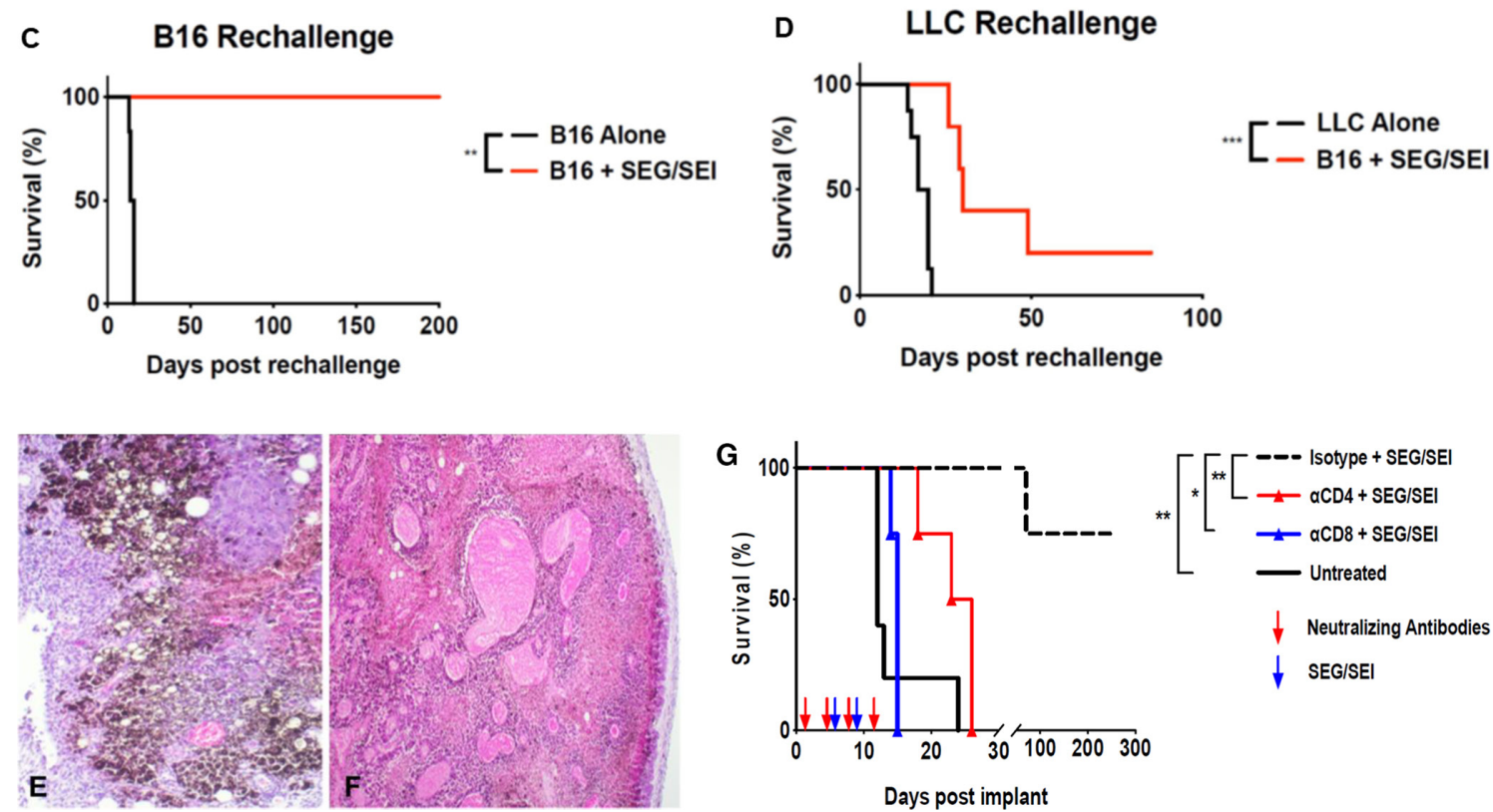

Figure 2 Survival of mice bearing established B16-F10 melanoma treated with SEG/SEl is shown. (A) C57BL/6 or (B) HLADQ8 tg mice received $2.5 \times 10^{5}$ B16-F10 cells IP on day 0. SEG/SEI, $50 \mu \mathrm{g}$ of each, was administered ip on days 6 and 9. Controls received B16-F10 tumor cells but no treatment (Kaplan-Meier with log-rank n=10-11). (C) On day 160, 4 surviving mice from (B) were rechallenged with $2.5 \times 10^{5}$ B16-F10 cells ip. Untreated controls received B16-F10 tumor alone. (D) an additional five mice from $(B)$ that survived 160 days were challenged with $2.5 \times 10^{5}$ Lewis lung carcinoma cells (LLC). Untreated controls received LLC cells alone (Kaplan-Meier with Log-rank). Histopathology analysis of B16-F10 omental tumors on day 13 after tumor inoculation from (E) untreated and (F) SEG/SEl -treated HLA-DQ8 TG mice is shown (H\&E ×10 magnification). (G) HLADQ8 tg mice received $2.5 \times 10^{5}$ live B16-F10 cells ip on day 0 , followed by the treatment with SEG/SEI, $50 \mu g$ of each, on days 6 and 9 and ip injections of anti-CD4, anti-CD8 and anti-lgG2b isotype control as shown (red arrows) (Kaplan-Meier with Logrank, $n=4-5) .{ }^{*} \mathrm{P}<0.05,{ }^{* *} \mathrm{p}<0.01$. 
cells both C57BL/6 and HLA-DQ8 tg mice exhibited omental metastases of comparable degree along with established histopathologic stroma and an angiogenic network (online supplemental figure 2). Taken together, these data indicate genetic compatibility of the C57BL/6derived B16-F10 melanoma in HLA-DQ8 tg mice and further show that the B16-F10 tumor was broadly established in both strains at the time SEG/SEI treatment was initiated.

Next, we compared the ability of SEG/SEI to prolong survival of mice with established B16-F10 melanoma in HLA-DQ8 tg and C57BL/6 mice. In initial studies, $\mathrm{C} 57 \mathrm{Bl} / 6$ mice received a tumorigenic dose of B16-F10 cells on day 0 and were subsequently injected with SEG and SEI, 50ug of each, on days 6 and 9. As predicted from their muted $\mathrm{T}$ cell proliferative response and diminished ability to generate $\mathrm{T}$ effector molecules in vitro, SEG/SEI did not prolong survival in C57BL/6 mice (figure 2A). In a further effort to unveil the antitumor properties of SEG/SEI we turned to HLA-DQ8 tg mice which faithfully induce more potent human-like responses to SAgs relative to wild type murine models. Strikingly, 9 of 11 HLA-DQ8 tg mice inoculated with B16-F10 melanoma and treated as above with SEG/ SEI survived for 160 days whereas all untreated HLADQ8 tg controls died within day 20 after tumor inoculation (figure 2B). Next, we determined whether the long-term surviving mice could mount a specific antitumor memory response against the parental melanoma. Thus, on day 160 , five of the nine surviving mice were rechallenged with a tumorigenic dose of Lewis lung carcinoma (LLC) cells while the remaining four mice were rechallenged with a tumorigenic dose of parental B16-F10 melanoma cells. The group rechallenged with B16F10 melanoma survived for an additional 200 days (figure 2C) whereas four of five mice challenged with LLC died within 50 days (figure 2D). Histology of untreated and SEG/SEI-treated tumors in HLA-DQ8 tg mice 13 days after initial tumor inoculation showed disseminated islands of melanoma cells in the untreated samples whereas sections from SEG/ SEI-treated mice displayed broadly propagated tumor necrosis engulfing the core and tumor periphery (figure $2 \mathrm{E}, \mathrm{F}$ ). Hence, while SEG/SEI treatment was ineffective against melanoma in C57BL/6 mice by turning to the HLA-DQ8 model we brought to light the potent ability of SEG/SEI to eradicate the tumor and induce long-term survival. This finding points to a key role of the HLA-DQ8 allele in enabling the tumoricidal effect of SEG/SEI. The striking capacity of HLA-DQ8 mice to reject a tumorigenic melanoma rechallenge but not rechallenge with LLC suggests that the SEG/SEI treatment induced specific anti-tumor memory in these mice. The tumor specificity of the memory response further suggested a role for melanoma neoantigens in processing and priming a tumor reactive $\mathrm{T}$ cell population that was subsequently expanded and enriched by SEG/SEI treatment.
Anti-CD4 or anti-CD8-specific antibodies abrogate the antitumor effect of SEG/SEI against established melanoma

Having shown that SEG/SEI could stimulate both CD4 +and CD8+T cells in splenocytes from HLA-DQ8 tg mice and induce long-term survival against established melanoma, we next determined the relative roles of CD8+ and $\mathrm{CD} 4+\mathrm{T}$ cells in the tumoricidal response. B16-F10 melanoma was inoculated into HLA-DQ8 tg mice on day 0 and SEG/SEI, 50 ug of each, injected ip on days 6 and 9. Individual groups received anti-CD4 or anti-CD8 specific antibodies while controls received isotype matched IgG2b antibodies. Results shown in figure $2 \mathrm{G}$ demonstrate attenuated survival of the SEG/SEI-treated mice receiving anti-CD 4 or anti-CD8 antibodies whereas $80 \%$ of mice receiving isotype control antibodies survived for 200 days after tumor inoculation. These data indicate a significant role for both $\mathrm{CD} 4+$ and $\mathrm{CD} 8+\mathrm{T}$ cells in the SEG/SEIinduced antitumor response in HLA-DQ8 tg mice.

\section{SEG/SEI-treated HLA-DQ8 tg mice show increased T effector cells along with minimal Tregs and myeloid cells in the tumor microenvironment (TME)}

In search of the $T$ cell population that generated the tumoricidal response, we next quantitated CD4+, CD8 + T cells, T effector cells, Tregs and myeloid cells in tumors of mice treated with SEG/SEI compared with untreated controls. HLA-DQ8 tg mice were inoculated with B16-F10 melanoma on day 0 and treated with SEG/SEI, 50 ug of each, on days 6 and 9 . Tumors were removed and analyzed on day 13. Untreated tumor bearing HLA-DQ8 tg mice served as controls. Tumors from SEG/SEI-treated HLADQ8 tg mice showed a striking increase of CD8+ and granzyme-B + T effector cells relative to tumors from untreated HLA-DQ8 tg mice (figure 3A,B). By contrast, myeloid cells in tumors from SEG/SEI-treated HLA-DQ8 tg mice were significantly reduced while Tregs were unchanged compared with the untreated controls (figure 3C,D). Ratios of $\mathrm{T}$ effector cells to Tregs or $\mathrm{T}$ effector cells to myeloid cells in SEG/SEI-treated HLA-DQ8 tg mice vs untreated HLA-DQ8 tg controls were significantly increased (figure 3 legend). Collectively, these findings point to CD8 + T effector cells as key mediators of the acute tumoricidal response and suggest that their antitumor effectiveness in the TME may be enhanced by the minimal presence of myeloid cells and suppressive Tregs.

\section{SEG/SEI-treated HLA-DQ8 tg mice display increased Th-1 cytokines in serum and TME}

Having shown that SEG/SEI activated IFN $\gamma$ in vitro, we now examined the effect of SEG/SEI treatment on production of IFN $\gamma$ and other cytokines in vivo in both serum and the TME. HLA-DQ8 tg mice were inoculated with a tumorigenic dose of B16-F10 cells on day 0 and subsequently injected with SEG and SEI, 50 ug of each, on days 6 and 9. Serum levels of TH-1 and TH-2 cytokine levels were evaluated 24 hours after each treatment on days 7 and 10 . On day 7, HLA-DQ8 tg mice exhibited a striking surge of IFN $\gamma$ with minimal changes in TNF $\alpha$ levels (figure 4A,B). On day 
10, however, following the second SEG/SEI treatment, the IFN $\gamma$ response was attenuated along with minimal levels of TNF $\alpha$ and interleukin-6 (IL-6) (figure 4A-C). By contrast TH-2 cytokines IL-4, IL-10 and IL-13 were not significantly elevated in HLA-DQ8 tg mice after either SEG/SEI treatment (figure 4E-F). Notably, the sharp increase in IFN $\gamma$ was unattended by any evident toxicity in HLA-DQ8 tg mice. The minimal toxicity was likely due to the muted levels of TNF $\alpha$ following both SEG/SEI treatments . TNF $\alpha$ has been shown to be causative in toxic shock in response to canonical SAgs, SpeA and SEB in HLA-DQ8 mice at doses significantly lower than d SEG/SEI as used here.$^{30-43}$ SEG/SEI in HLA-DQ8 mice therefore displayed a remarkable ability to induce potent IFN $\gamma$ and $\mathrm{T}$ effector cell responses while sharply curtailing TNF $\alpha$ production and preventing the appearance of toxic shock.

Next, we analyzed B16-F10 tumors obtained from SEG/SEI-treated HLA-DQ8 tg mice for the presence of cytokines on day 13 following tumor inoculation. HLA-DQ8 tg mice received a tumorigenic dose B16-F10 melanoma cells on day 0 and were treated with SEG/ SEI, $50 \mu \mathrm{g}$ of each, on days 6 and 9. Controls were inoculated with tumor but received no treatment. SEG/SEItreated HLA-DQ8 tg mice showed striking increases in IFN $\gamma$, TNF $\alpha$ and IL- 6 in the TME relative to untreated controls whereas TH-2 cytokines IL-4 and IL-10 were not significantly altered (figure $4 \mathrm{I}$ ). The tumoricidal function of IFN $\gamma$ coupled with its ability to upregulate MHCII expression on melanoma cells and prime cytolytic CD8 $+\mathrm{T}$ cells likely contributed significantly to the acute anti-tumor response. ${ }^{44} \mathrm{TNF} \alpha$. also noted in the TME. has been shown to synergize with IFN $\gamma$ in tumor cytolysis. ${ }^{45}$ The presence of IFN $\gamma$ and TNF $\alpha$ s in the TME, not seen in untreated controls, suggests that these are the major cytokine mediators of to the acute tumoricidal effect in SEG/SEI-treated HLA-DQ8 $\operatorname{tg}$ mice.

\section{SEG/SEI-treated HLA-DQ8 tg mice display increased chemokines in the TME}

A hypothetical barrier to successful immunotherapy is inadequate recruitment of activated $\mathrm{T}$ cells and $\mathrm{T}$ effector cells into the tumor sites. An optimal chemokine profile in the melanoma TME may be critical for recruitment of activated $\mathrm{T}$ cells. While several chemokiness are known to be activated by SAgs, ${ }^{44}{ }^{46}$ the ability of SAg to induce chemokine accumulation in tumors has not been demonstrated. To evaluate intratumoral chemokines, HLA-DQ8 tg mice were inoculated ip with a tumorigenic dose of B16-F10 melanoma and treated with SEG/SEI, $50 \mu \mathrm{g}$ of each, on days 6 and 9. Controls received tumor cells but no treatment. Omental tumors were removed on day 16 and evaluated for chemokines. SEG/SEI-treated mice showed significant increases in CCL2,CCL3, CCL4, CCL5, CXCL9, CXCL10 chemokines relative to the untreated controls (figure 4J). Interestingly, Harlin et al, identified the very same chemokine expression profile in treatment-responsive metastatic melanomas and further showed that each of them was
A

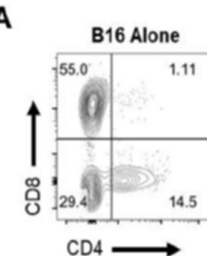

B
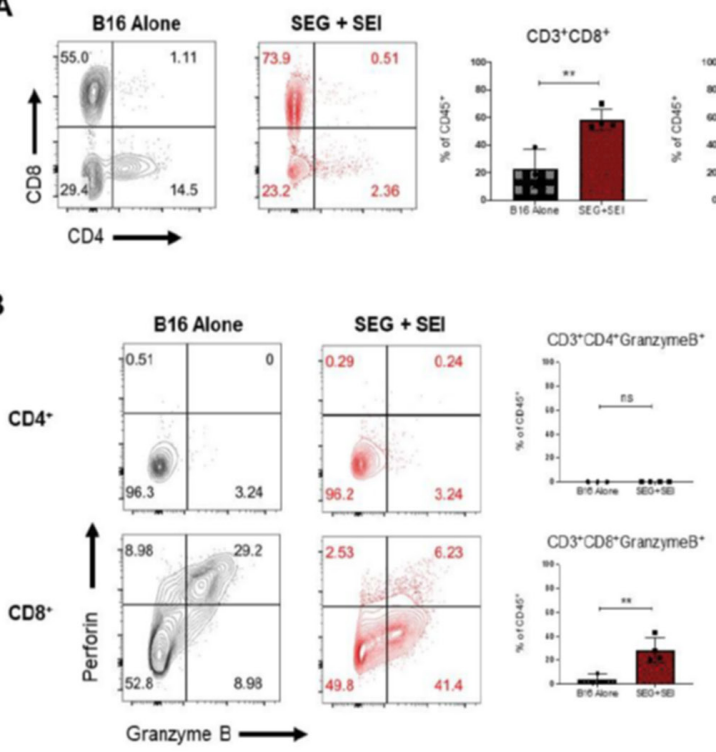

C
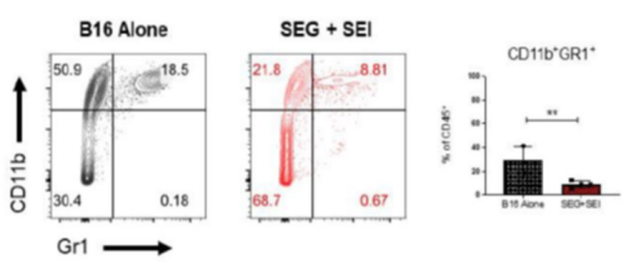

D

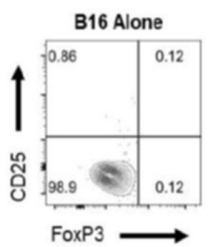

Figure 3 Evaluation of T cells and myeloid cells in B16-F10 tumors from HLA-DQ8 tg mice treated with SEG/SEI is shown. HLA-DQ8 tg mice received $2.5 \times 10^{5}$ live B16-F10 cells IP on day 0 , followed by the treatment with SEG/SEI, $50 \mu \mathrm{g}$ of each, on days 6 and 9 . Controls were inoculated with tumor but received no treatment. On day 13, tumors were excised and assayed for (A) CD3 +CD8+cells, (B) CD8 ${ }^{+}$granzyme B ${ }^{+}$cells, (C) CD25 FoxP3 ${ }^{+}$cells, (D) $\mathrm{CD}^{+} 11 \mathrm{~b}^{+} \mathrm{Gr}^{+}$cells. ANOVA with Tukey post test. $n=3$. ${ }^{*} P<0.05,{ }^{* *} p<0.01$,. Ratio of $C D 8^{+}$granzme $B^{+}$cells to $C D 25^{+} F o x p 3^{+}$cells $\geq 10: 1(n=4, p=0.01)$ and ratio CD8+ granzyme $B+$ cells to $C D 11 b+G R 1+$ cells=3.9:1 $(n=4, p=0.03)$. Data expressed as mean $\pm S D$, Student's t test, two tailed. ANOVA, analysis of variance; ns, not significant. 
A

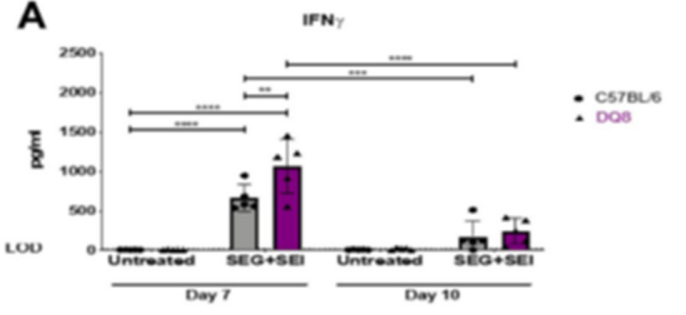

B

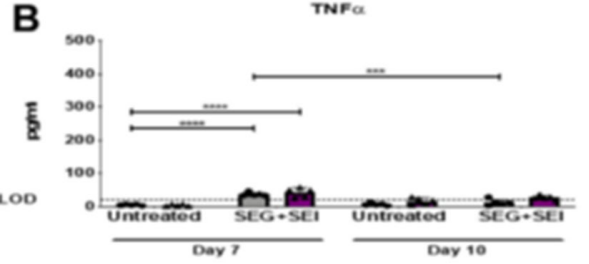

C
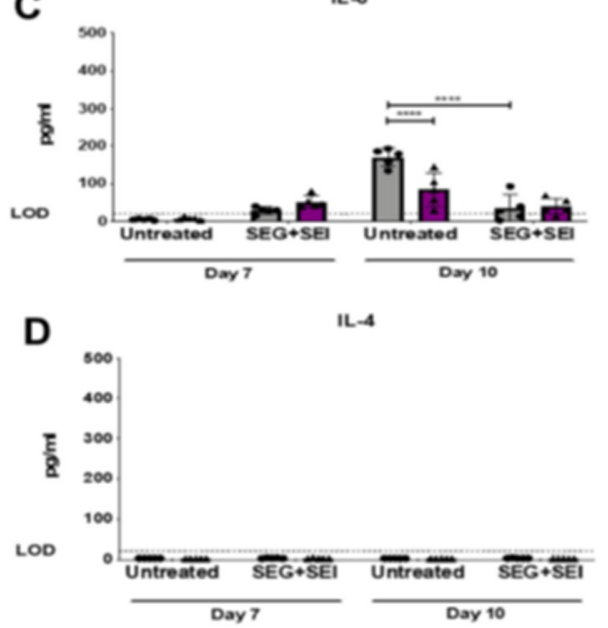

I

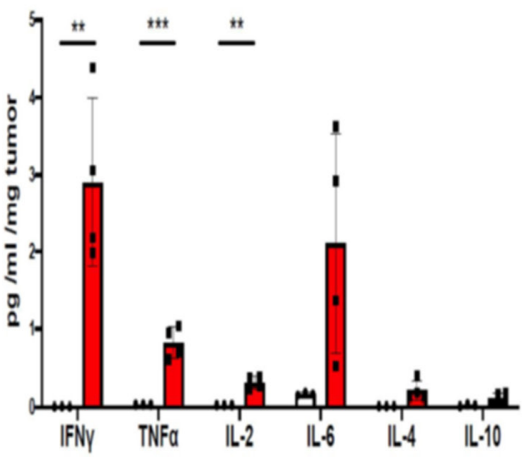

- сотв⿻上丨 Dos

B16 Untreated - B16+SEGSEL
E

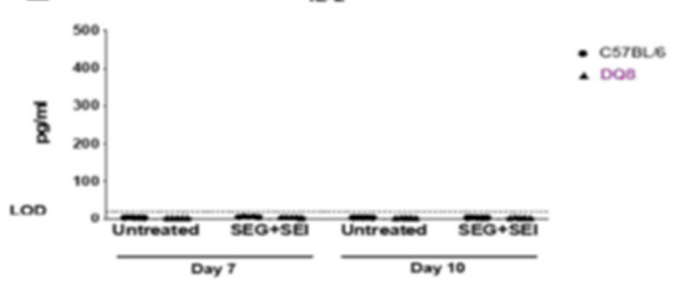
- Cs78le
Dos Cstale $\therefore$ Dos
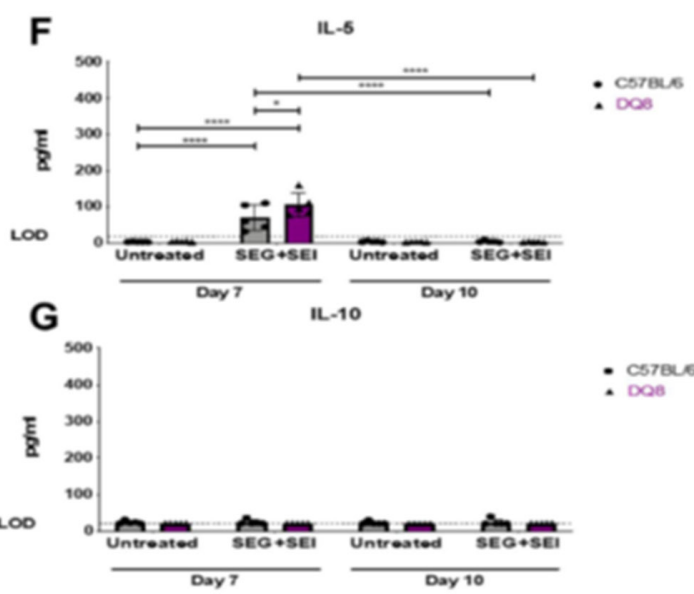

- Cstale

H

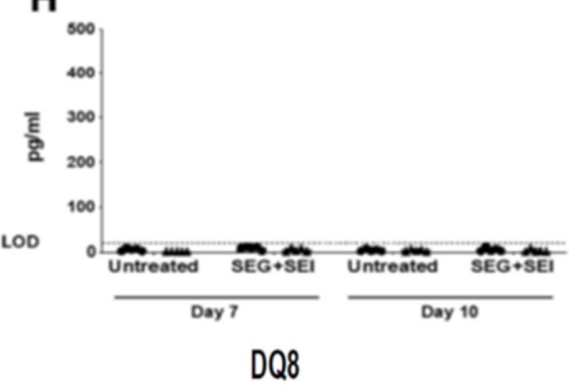

- C57BL - Dos

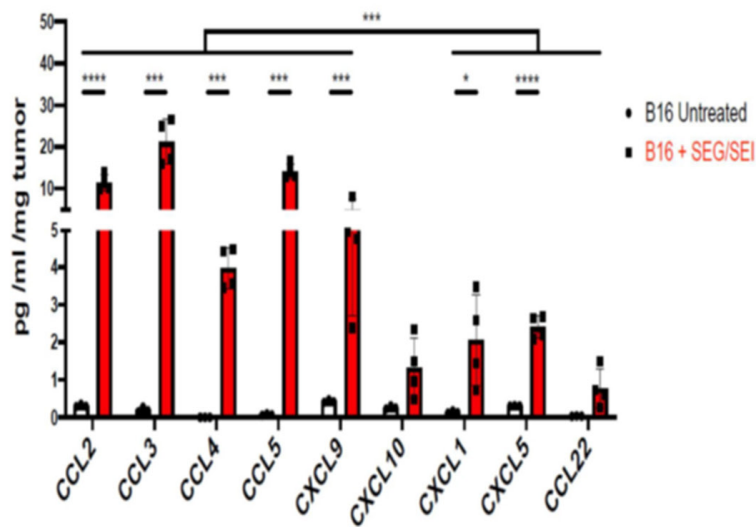

Figure 4 Evaluation of cytokines and chemokines in serum and tumor from HLA-DQ8 tg mice treated with SEG/SEl is shown. (A-H) HLA-DQ8 tg and C57BL/6 mice received $2.5 \times 10^{5}$ B16-F10 cells ip and were treated with SEG/SEI, $50 \mu g$ of each, ip on days 6 and 9 . Controls were inoculated with $r$ tumor but received no SEG/SEI treatment. Serum cytokines were analyzed 24 hours after each SEG/SEI treatment, $n=4-5$. (I, J) HLA-DQ8 tg mice received $2.5 \times 10^{5}$ live B16-F10 cells ip on day 0 , followed by the treatment with SEG/SEl, $50 \mu \mathrm{g}$ of each, on days 6 and 9. Controls were inoculated with B16-F10 cells lip but received no treatment. On days 13 and 16 tumors were assayed for (I) cytokines and $(\mathrm{J})$ chemokines, respectively. Data expressed as mean \pm SD. ANOVA with Tukey post-test. $n=3 .{ }^{*} \mathrm{P}<0.05,{ }^{* *} \mathrm{p}<0.01,{ }^{* * \star} \mathrm{p}<0.001,{ }^{* * \star *} \mathrm{p}<0.0001$. ANOVA, analysis of variance.

efficient in chemotaxis of activated T cells. ${ }^{47}$ Each of these chemokines displayed a significantly higher level than CXCL5 and CXCL1 and CCL22 chemokines that have been shown to recruit PMN/MDSCs, PMNs or Tregs, respectively (figure 4J). ${ }^{48-50}$ Collectively, these findings suggest that the intratumoral chemokine constellation identified here after SEG/SEI treatment contributed to the recruitment T effector cells in the TME. 

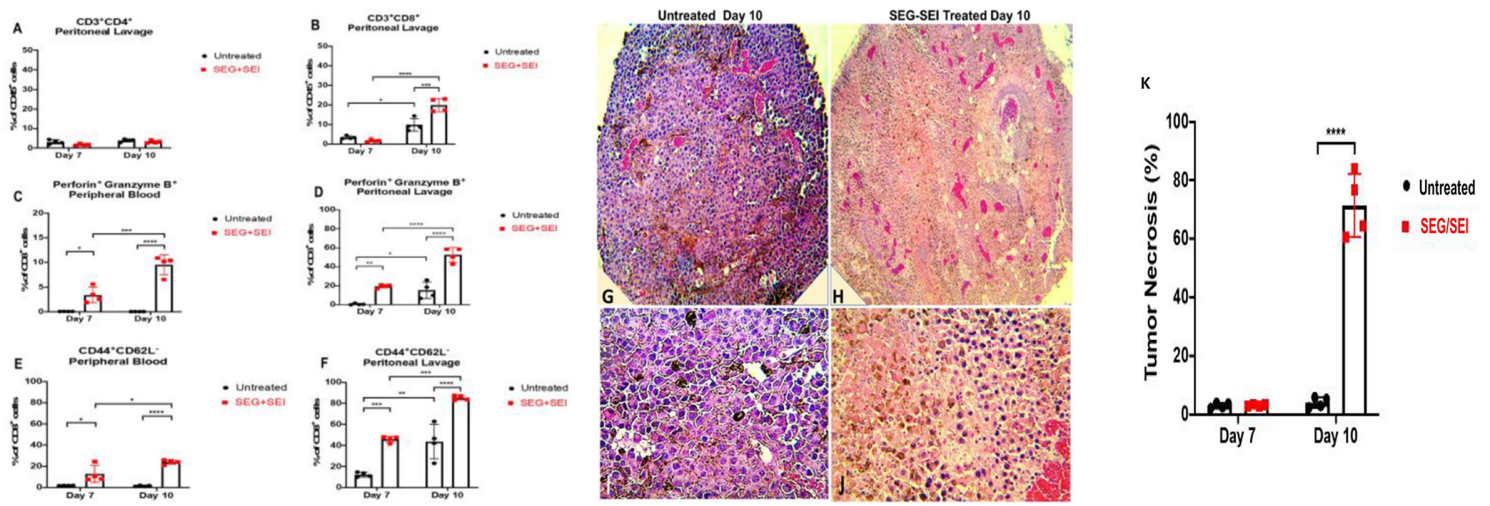

Figure 5 T cell recruitment to tumor injection site after administration of SEG/SEI to HLA-DQ8 TG mice is shown. HLADQ8 TG mice received $2.5 \times 10^{5}$ B16-F10 cells ip and were treated with SEG/SEI, $50 \mu$ g of each, IP on days 6 and 9 . Controls were inoculated with tumor but received no treatment. Twenty-fourhours after each SEG/SEI treatment peritoneal lavage and peripheral blood were assayed for $(A, B) C D 4$ +and CD8+T cells, $(C, D)$ perforin-granzyme B+T effector cells, and (E, F) CD44 +CD62L- cells. (G-J) Histopathology of omental tumor sections on day 10 from untreated and SEG/SEl-treated mice is shown. $(\mathrm{H}, \mathrm{E}) \times 10$ magnification $(\mathrm{G}, \mathrm{I})$; x40 magnification (I, J). Quantification of histological necrosis in tumor sections from untreated and SEG/SEl-treated mice on days 7 and 10 is shown (K). $n=3-4$. Data expressed as mean $\pm S D$. ${ }^{*} P<0.05,{ }^{* *} p<0.01,{ }^{\star * \star} p<0.001$, ${ }^{\star \star \star *} \mathrm{p}<0.001$.

\section{SEG/SEI-treated HLA-DQ8 tg mice recruit T effector cells to the site of tumor injection}

Untreated tumors generally contain only small numbers of $\mathrm{T}$ effector cells tumor site. While SAgs have been shown to recruit activated $T$ cells to their injection site, ${ }^{51}$ they have not been shown to recruit $\mathrm{T}$ cell to tumors, We, therefore, determined whether SAg injected into the same peritoneal site as tumor inoculation could induce robust trafficking of $\mathrm{T}$ cells to established peritoneal tumors. Effector T cells once situated in the peritoneum are known to traffic rapidly to tumor niches in the omentum. ${ }^{52}$ To test this concept, HLA-DQ8 tg mice were inoculated ip with a tumorigenic dose of B16-F10 melanoma cells and treated with SEG/SEI ip on days 6 and 9. Twenty-four hours after each treatment on days 7 and 10 , tumors were removed and both peritoneal lavage and peripheral blood were assessed for the presence of $\mathrm{T}$ effector cells. Controls were inoculated with B16-F10 cells on day 0 but received no treatment. On days 7 and 10, SEG/SEI treated mice showed striking absolute and incremental increases in the number of activated $\left(\mathrm{CD} 44^{+} \mathrm{CD} 62 \mathrm{~L}^{-}\right.$) and CD8 +effector (granzyme-perforin+) $\mathrm{T}$ cells in both peripheral blood and peritoneal lavage compared with untreated controls (figure 5A-F). Analysis of omental tumor in SEG/SEI treated mice on day 10 showed a significantly greater degree of tumor necrosis relative to the untreated control encompassing a mean of $70 \%$ of the tumor area (figure $5 \mathrm{G}, \mathrm{K}$ ). These findings indicate that SEG/SEI recruited $\mathrm{T}$ effector cells to the site of tumor injection in the peritoneal cavity wherein they traffic to tumor niches in the omentum and likely constitute the major $\mathrm{T}$ cell population mediating the tumoricidal response. The SEG/SEI-mediated recruitment of $\mathrm{T}$ effector cells to the tumor site thus appears to convert the tumor from 'cold' to 'hot'. The concurrent increase of effector $\mathrm{T}$ cells in both the peripheral blood and peritoneum after ip injection of SEG/SEI suggests that the peritoneal effector $\mathrm{T}$ cell population may have originated, in part, from an SEG/SEI-activated effector T cell population in the peripheral blood.

\section{Vaccination with irradiated melanoma cells followed by SEG/SEI affords protection of HLA-DQ8 $\mathrm{tg}$ mice from living melanoma cell challenge}

We next determined whether SEG/SEI could enhance an antitumor immune response to vaccination with radiationinactivated B16-F10 melanoma cell and confer protection from live B16-F10 challenge in HLA-DQ8 tg mice. Tumor cells exposed to ionizing radiation often carry new mutations in genes encoding proteins involved in DNA-repair mechanisms and cell-cycle regulation some of which are likely to be immunogenic. ${ }^{53}$ To test this notion, HLADQ8 mice were vaccinated with $1 \times 10^{6}$ irradiated B16-F10 melanoma cells on day -13 , treated with SEG and SEI, $50 \mathrm{ug}$ or each, ip on days -7 and day -3 and challenged with $2.5 \times 10^{5}$ viable B16-F10 cells on day 0 . Control mice received viable $\mathrm{B} 16-\mathrm{F} 10$ cells alone, irradiated tumor cell vaccination on day -13 plus viable B16-F10 cells on day 0 0r SEG/SEI on days -7 and -3 plus viable B16-F10 cells on day 0. HLA-DQ8 tg mice receiving irradiated tumor cell vaccination followed by SEG/SEI survived significantly longer after live melanoma challenge than all controls (figure 6A). We next determined whether the antitumor protection induced by irradiated melanoma cell vaccination combined with SEG/SEI treatment could protect surviving mice against a challenge with the parental tumor. All HLA-DQ8 tg mice that survived for more than 60 days after tumor inoculation were rechallenged with a tumorigenic dose of melanoma cells and remained tumor-free for the succeeding 140 days (figure 6A). These results show that vaccination followed by SEG/SEI administration elicits anti-melanoma protection against primary and 

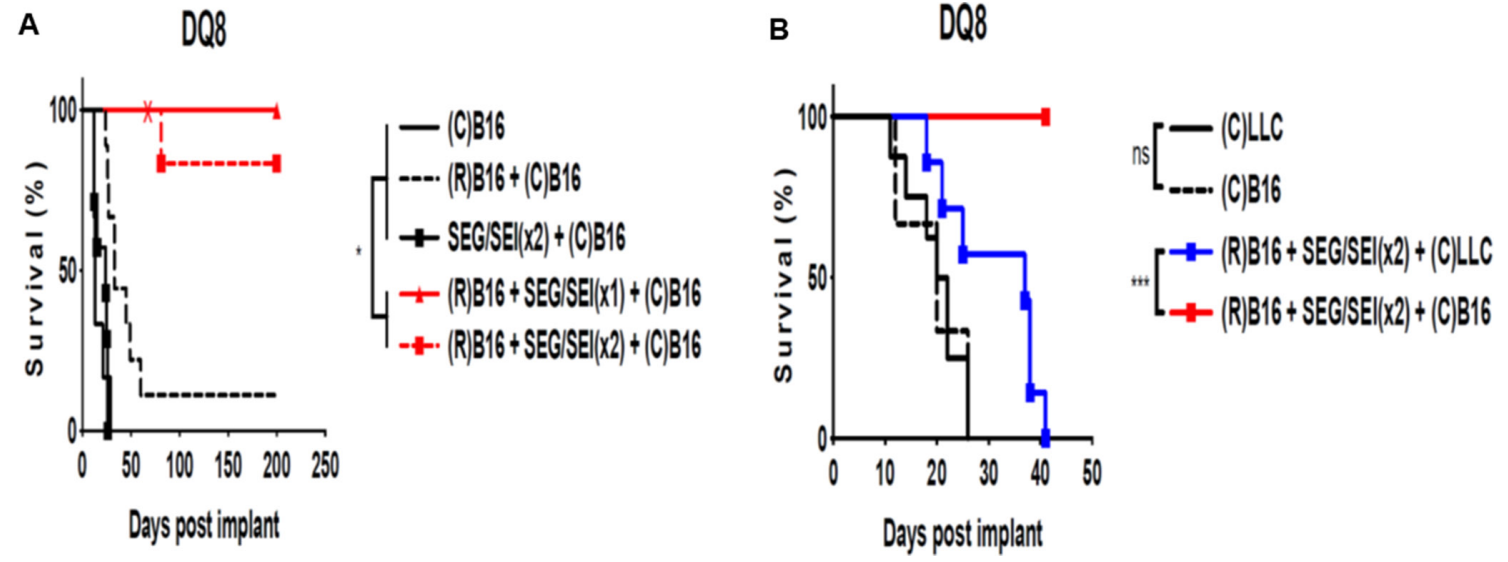

Figure 6 Vaccination with inactivated B16-F10 melanoma plus SEG/SEl in HLA-DQ8 tg mice induces long term survival. (A) HLA-DQ8 tg mice were treated with $1 \times 10^{6}$ irradiated (15000 rads) B16-F10 melanoma cells ip on day -13 injected with SEG/SEI $50 \mu \mathrm{g}$ of each ip on days -7 and -3 and challenged with $2.5 \times 10^{5}$ live B16-F10 cells IP day 0 . Controls received live melanoma challenge alone on day 0 or irradiated B16-F10 cells on day -13 plus $2.5 \times 10^{5}$ live melanoma challenge on day 0 or SEG/SEI on days -7 and -3 plus $2.5 \times 10^{5}$ live melanoma cells.on day 0 . HLA-DQ8 tg mice surviving $>60$ days ('X') were rechallenged with $2.5 \times 10^{5}$ live B16-F10 cells ip (X). (B) HLA-DQ8 Ttg mice were inoculated with $1 \times 10^{6}$ irradiated (15000 rads) B16-F10 melanoma cells ip on day -13 , injected with SEG/SEI, $50 \mu \mathrm{g}$ of each, ip on days -7 and -3 and challenged with $2.5 \times 10^{5}$ live B16-F10 cells or Lewis lung carcinoma cells on day 0 . Controls received $2.5 \times 10^{5}$ live B16-F10 cells or Lewis lung carcinoma cells alone on day 0 . Kaplan-Meier curves with log-rank test, $n=10$. ${ }^{*} P<0.05,{ }^{* \star *} p<0.001$. Acronym ' $R$ ' denotes irradiated tumor cell vaccination on day -13 and ' $C$ ' indicates challenge with either B16-F10 melanoma or Lewis lung carcinoma tumor cells on day 0 . ns, not significant.

secondary B16-F10 melanoma challenge. Next, we examined the anti-tumor specificity of the response induced by vaccination with irradiated B16-F10 cells and SEG/SEI treatment. HLA-DQ8 tg mice were vaccinated with $1 \times 10^{6}$ irradiated B16-F10 cells on day -13 , treated with SEG and SEI, $50 \mu \mathrm{g}$ of each, on days -7 and -3 and challenged with $2.5 \times 10^{5}$ viable B16-F10 or LLC cells on day 0 . All mice pretreated with irradiated B16-F10 cells plus SEG/SEI and challenged with viable B16-F10 cells demonstrated survival to day 40 whereas none of the mice similarly vaccinated and treated with SEG/SEI but challenged with LLC cells survived beyond 40 days (figure $6 \mathrm{~B}$ ). Hence, the protection induced by the vaccination regimen of irradiated tumor cells plus SEG/SEI was tumor specific. To better understand the immune basis of the recall response of vaccinated mice to tumor challenge HLA-DQ8 tg mice were vaccinated with $1 \times 10^{6}$ irradiated B16-F10 cells on day -13 , treated with SEG/SEI, $50 \mu \mathrm{g}$ of each. ip of each, on days -7 and -3 and challenged with $2.5 \times 10^{5}$ live B16F10 cell on day 0 . On day 40 , they were rechallenged $2.5 \times 10^{5}$ live B16-F10 cells and 6 days later peritoneal lavage and omental tumors were examined. HLA-DQ8 mice tinoculated with B16-F10 tumor cells on day 0 and sacrificed 6 days later served as untreated controls. Evaluation of peritoneal lavage cells from vaccinated and tumor rechallenged mice showed significant elevations of
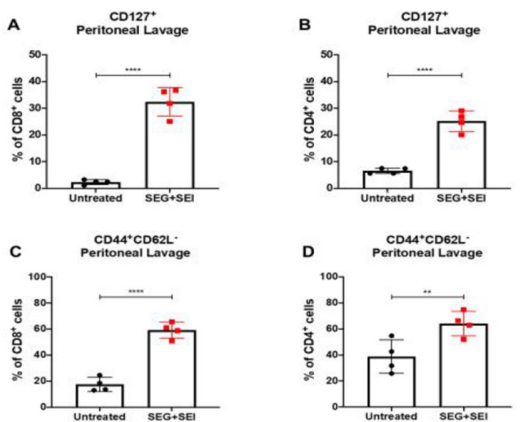
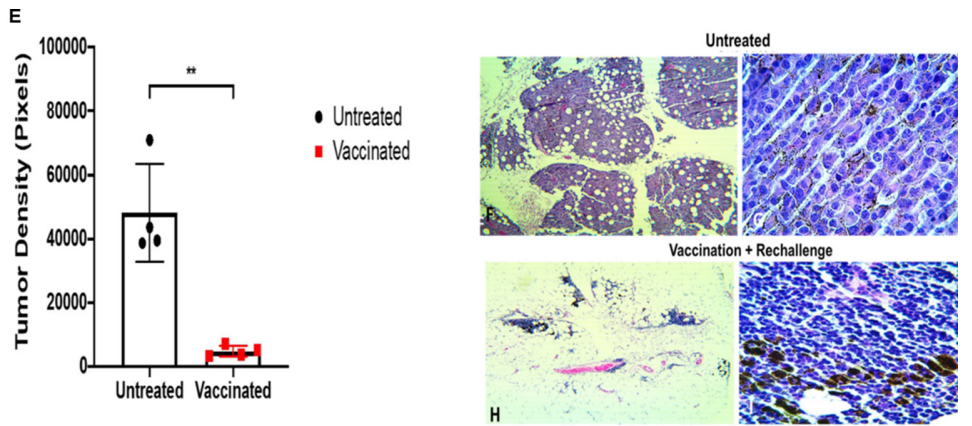

Figure 7 Recall response of vaccinated HLA-DQ8 mice to live melanoma challenge is shown. HLA-DQ8 tg mice were vaccinated with $1 \times 10^{6}$ irradiated B16-F10 cells on day -13 , treated with SEG/SEI, $50 \mu \mathrm{g}$ of each, on days -7 and -3 and challenged with $2.5 \times 10^{5}$ live B16-F10 cells on day 0 . On day 40 , they were rechallenged $2.5 \times 10^{5}$ live B16F10 cells and 6 days later (day 46) omental tumor and peritoneal lavage cells were examined. Untreated HLA-DQ8 tg miceinoculated with B16-F10 tumor cells on day 0 and sacrificed 6 days later served as controls. Analysis of peritoneal lavage cells from untreated and vaccinated mice for the presence of CD127+, and CD44+CD62L- T cells is shown (A-D). Quantitation of omental tumor density in sections from vaccinated and untreated mice using the ImageJ software is shown (E). Sections of omental tumors from untreated $(F, G)$ and vaccinated mice $(H, I)$ are shown. $(H, E) \times 5$ magnification $(F, H)$ and $X 40$ magnification $(G, I)$. Data expressed as mean $\pm S D ; . n-3-4,{ }^{* *} p<0.01,{ }^{* * *} p<0.001$. 
activated (CD44+CD62L-) and memory (CD127+) T cells relative to the untreated controls (figure 7A-D). ${ }^{54}$ Total omental tumor density in vaccinated mice was 11-fold less than the untreated controls (figure $7 \mathrm{E}$ ). Histologicanalysis of all omental tumor deposits in vaccinated and untreated control mice showed striking differences (figure $7 \mathrm{~F}-\mathrm{H}$ ). Whereas control tumor cells were situated in discrete tumor nodules with well developed stromal matrix (figure $7 \mathrm{~F}, \mathrm{G}$ ), tumor cells in the vaccinated mice were positioned amid large aggregates of mononuclear cells devoid of organized tumor matrix or distinct tumor nodules (figure $7 \mathrm{H}, \mathrm{I}$ ). These mononuclear cells aggregates likely constitute omental milky spots infiltrated by tumor cells. Vaccination, therefore, reduced the density of omental tumor cells and constrained the formation of organized tumor nodules relative to untreated controls. Collectively, these data indicate that vaccination with radiation-inactivated B16-F10 cells plus SEG/SEI affords tumor specific, and long-term anti-tumor protection against B16-F10 challenge. This protection appeared to be mediatedby $\mathrm{f}$ effector and memory $\mathrm{T}$ cell populations.

\section{SEG/SEl toxicity in HLA-DQ8 tg mice}

SEG/SEI treatment in HLA-DQ8 tg mice was well tolerated. There were no acute deaths and mice showed no signs of inanition, anorexia or disability during or after treatment. Arthritis susceptible HLA-DQ8 tg mice ${ }^{55}$ treated with SEG/SEI also exhibited no clinical signs of arthritic joint swelling, ambulatory impairment, polydipsia or weight loss during 360 days of observation.

\section{DISCUSSION}

In a discovery-driven effort to unearth new anticancer drugs, we introduce a heretofore unrecognized binary complex comprizing non-canonical SEG/SEI SAgs together with endogenous MHCII HLA-DQ8 allele in humanized mice. This pairing displayed striking tumoricidal strength and long-term melanoma survival (>360 days) entirely devoid of toxicity in both vaccinated mice and mice with established melanoma. SEG/SEI were chosen over canonical SAgs because they are devoid of sero-reactive neutralizing antibodies that have nullified the efficacy of canonical SAgs in human cancer trials. The HLA-DQ8 allele was selected for its large antigen groove and ability to functionally engage both SAgs and melanoma neoantigens. In humanized mice, the SEG/ SEI (HLA-DQ8) complex orchestrated an acute tumoricidal response marked by robust $\mathrm{T}$ effector cell and IFN $\gamma$ generation while asymmetrically silencing TNF $\alpha$. This constrained TNF $\alpha$ response was surprizing since canonical SAgs in this very same model induce TNF $\alpha$-mediated toxic shock. In addition, the complex unleashed a broad tumoricidal network featuring chemotactic mobilization and recruitment of CD8 +effector T cells to the TME while quelling the appearance of suppressive Tregs and myeloid cells. The anttumor response culminated in specific antitumor memory whereby long-term melanoma survivors rejected the parental melanoma but succumbed to challenge with the LLC. The novel revelation that SEG/SEI and HLA-DQ8 humanized model can unleash a striking tumoricidal response and tumoricidal network devoid of toxicity is slated to reinvigorate the field and forge a pathway to clinical translation.

We bring forth a broad range of evidence in support of the contention that the key mediators of the antitumor response induced by SEG/SEI in HLA-DQ8 mice are granzyme-perforin producing $\mathrm{CD} 8+\mathrm{T}$ cells and IFN $\gamma$ as follows: (1) Deletion experiments showed that the antitumor response induced by SEG/SEI in HLA-DQ8 mice was CD4 +and CD8+T cell dependent (figure 2G). (2) Analysis of $\mathrm{T}$ cell phenotypes in tumor lysates from the TME of SEG/SEG treated mice at day 10 (figure 5C,D and $\mathrm{G}, \mathrm{H}$ ) and day 13 (figures 2B,E,F and 3B) showed significant infiltration by $\mathrm{CD} 8+\mathrm{T}$ granzyme-perforin $+\mathrm{T}$ effector cells and IFN $\gamma$. This was associated with extensive tumor necrosis indicative of a major antitumor pathological effect. These changes were not seen in the untreated controls. (3) SEG/SEI produced a sharp surge of serum levels of IFN $\gamma$ in SEG/SEI-treated mice not seen in the untreated controls (figure $4 \mathrm{~A}$ ). IFN $\gamma$ was also identified as the predominant cytokine in lysates of regressing tumors at day 16 (figure 4I). (4) In vitro studies confirmed the ability of SEG/SEI to mount a robust $\mathrm{T}$ effector cell and IFN $\gamma$ responses in naïve HLA-DQ8 T cells (figure $1 \mathrm{C}-\mathrm{F}$ ). (5) The SEG/SEI-mediated anti-tumor response was specific for melanoma since these very same mice succumbed to challenge with the LLC (figure 2B,C,D). (6) In HLA-DQ8 mice vaccinated with irradiated melanoma cells and rechallenged with live melanoma cells, both $\mathrm{T}$ effector cells and $\mathrm{T}$ memory cells were identified in the TME but not seen in the untreated controls (figure 7A-D).

Moreover, the tumoricidal response in SEG/SEItreated HLA-DQ8 mice cannot be attributed to cytokine storm since these mice exhibited no evident toxicity or toxic shock that typifies such storm. Remarkably, elevated $\mathrm{TNF} \alpha$ levels which are the hallmark of 'toxic shock' were subdued in SEG/SEI-treated mice (figure 4B). Furthermore, the specificity of antitumor effect after melanoma rechallenge in SEG/SEI-treated mice supports our contention that a non-specific 'cytokine storm' is not the basis of the tumoricidal response. If cytokine storm were the cause of the anti-tumor response then long-term melanoma survivors would have been expected to resist challenge with both live melanoma and LLC cells. That only the long-term melanoma survivors rejected the live tumor challenge strongly suggests that specific $\mathrm{T}$ effector memory cells were involved in the anti-tumor effect. Indeed, such memory $\mathrm{T}$ cells were identified in the TME of mice after rechallenge with live melanoma.

The muted toxicity of SEG/SEI mice in the presence of the potent antitumor effect appeared to be based on the constrained TNF $\alpha$ response in HLA-DQ8 mice (figure 4B). This response was reliant on SEG/SEI since other SAgs deployed in HLA-DQ8 mice at lower doses 
induced TNF $\alpha$-mediated toxicity. ${ }^{30}{ }^{41-43}$ Diverse cytokine reactions and toxicity in humanized MHCII transgenic mice have been noted in response to SAgs and ascribed to their divergent affinities and binding conformations with human MHCII molecules. ${ }^{145657}$ Such differential cytokine responses also appear to be dependent on interactions of conserved SAg motifs with the B7-CD28 axis. ${ }^{13}{ }^{14}$ Indeed, cytokine-based toxicity of SAgs was abrogated in humanized MHCII mice deficient in CD28 or by treatment with anti-CTLA-Fc antibody. ${ }^{4258}$ Taken together, these findings indicate that SEG/SEI works uniquely with HLA-DQ8 allele and possibly the B7-CD28 axis to preserve melanoma specific anti-tumor $\mathrm{T}$ cell response while silencing cytokine-based toxicity.

Our deletion experiments showing that CD4 +in addition to CD8 + Tcell are required for the SEG/SEImediated induced antitumor response supports key role of the HLA-DQ8 allele in the antitumor response. (figure 2G). CD8 +T effector cells recruited to tumor sites and found together with IFN $\gamma$ in the TME appear to the major effectors of the antitumor response.MHCII molecules, however, have also been shown to play an important role in processing tumor neoantigens, activating $\mathrm{CD} 4+\mathrm{T}$ cells, priming tumor specific $\mathrm{CD} 8+\mathrm{T}$ effector cells and collaborating with them in an effective antitumor response ${ }^{5960}$ Recent reports suggest a role of HLA-DQ8 in binding melanoma neoantigens and presenting them to CD4 +cells. ${ }^{34} 3536$ The notion that these tumor neoantigens are involved in the SEG/SEImediated anti-tumor response ${ }^{61} 62$ is supported by tumor specific memory exhibited by long-term melanoma survivors that resisted autologous tumor rechallenge for more than 160 days while succumbing to the LLC (figures 2B and 6A). Indeed, B16-F10 melanoma-derived neopeptides with high affinity for MHCII have conferred protection against established melanoma when delivered on cationic liposomes. ${ }^{36}$ We surmise that shortly after tumor inoculation, HLA-DQ8 processed melanoma neopeptides and primed CD $4+\mathrm{T}$ cells. Subsequent SEG/SEI administration expanded these antigen-primed T-cells in accord with SAg's ability to initiate $\mathrm{T}$ cell recall responses. ${ }^{10-13}$ HLA-DQ8 allele is thereby repurposed in a hitherto unappreciated therapeutic role of priming a population of melanoma specific $\mathrm{T}$ cellsand serving as a scaffold for an SEG/SEI-mediated anamnestic T-cell-mediated antitumor response

SEG/SEI also generated $\mathrm{T}$ cell chemotactic molecules (figure $4 \mathrm{~J}$ ) that enabled recruitment of $\mathrm{CD} 8+\mathrm{T}$ effector cells to the site of tumor injection and the TME (figure 3A,B). Such effector cell recruitment and consequent tumor cell necrosis indicates that SEG/SEI can convert the tumor from 'cold' to 'hot' (figure 5A-J). SEG/SEI further stimulated a surge of IFN $\gamma$ output from both CD4 +and CD8+T cells (figures 1C, D and 4A). By days 13-16 after tumor implant, the TME was infiltrated by $\mathrm{CD} 8+\mathrm{T}$ effector cells along with IFN $\gamma$ and $\mathrm{TNF} \alpha$ that appear to constitute the major tumoricidal effectors (figures $3 \mathrm{~A}, \mathrm{~B}$ and $4 \mathrm{I}$ ). The acute tumoricidal response (figure 5G,H) was therefore likely mediated by clones of primed melanoma-specific effector T-cells while a memory cell population derived from this lineage provided tumor specific protection against late melanoma challenge at day 160 (figure 2C). The latter feature constitutes a critical distinction from $\mathrm{T}$ cell agonist anti-PD-1 whose long-term T-cell memory response is epigenetically constrained. ${ }^{63}$

IFN $\gamma$ produced by $\mathrm{CD} 4+$ and $\mathrm{CD} 8+\mathrm{T}$ cells in response to SEG/SEI emerges in a major role as a tumoricidal effector of its own while also priming tumor reactive CD8 + T cells. ${ }^{44}$ Following SEG/SEI injection on day 6 SEG/SEI-treated mice displayed robust IFN $\gamma$ production (figure 4A). This likely upregulated MHCII expression on melanoma cells enabling them to bind SEG/SEI and activate CD8 + T effector cells. ${ }^{45} 64$ The same IFN $\gamma$ surge was likely responsible for constraining Treg differentiation to account for the minimal Treg presence noted in the TME after SEG/SEI treatment (figures $1 \mathrm{G}$ and 3D). ${ }^{65}$ Such Treg reduction in the TME would also likely support the CD8 +effector T cell response. Melanoma specimens from subjects with improved prognosis exhibited an assemblage of chemokines that were strikingly similar to the chemokine profile we detected in tumors after SEG/ SEI treatment ${ }^{47}$ (figure $4 \mathrm{~J}$ ). Several of these have been shown to be IFN $\gamma$ and SAg inducible and are known to recruit effector $\mathrm{T}$ cells akin to those we noted in the TME of SEG/SEI-treated mice (figure 5A-F).

Despite the subdued serum TNF $\alpha$ response sufficient to silence toxic shock (figure 4B), SEG/SEI was still able to induce ample TNF $\alpha$ to contribute to the tumoricidal response. Indeed, we identified $\mathrm{TNF} \alpha$ together with IFN $\gamma$ in the TME of SEG/SEI-treated HLA-DQ8 tg mice (figure $4 \mathrm{I}$ ). TNF $\alpha$ is reported to synergize in SAg-mediated tumoricidal responses and has been implicated in a selfsustaining feed-forward inflammatory process. ${ }^{4566}$ The unique persistence in time of high affinity, zinc-binding SAgs such as SEI to MHCII on the surface of antigenpresenting cells may also enable a self-perpetuating cycle that generates T effector cells, IFN $\gamma$ and T cell memory. ${ }^{67}$ Collectively, the combined presence of IFN $\gamma, \mathrm{TNF} \alpha$ and $\mathrm{T}$ effector cells in the TME strongly supports their role as key mediators of a dynamic tumoricidal process that culminates in long-term memory and challenge-resistant melanoma survival. A schematic representation of the proposed chain of events is shown in figure 8 .

Investigators have long recognized that $\mathrm{SAg}$ behavior in humanized HLA-DQ8 mice is highly predictive of toxic shock in humans. ${ }^{41-43}$ Hence, the potent antitumor effects of SEG/SEI without toxicity in humanized HLADQ8 mice portend their successful clinical translation. In support of this concept, SEG and SEI as part of a staphylococcal filtrate were administered parenterally during treatment of advanced lung cancer and exhibited no significant constitutional or hemodynamic toxicity. ${ }^{68}{ }^{69} \mathrm{In}$ clinical translation, it may be desirable to shelter SEG/ SEI from engaging other MHCII alleles in vivo. This may be accomplished ex vivo by linking SEG-SEI to HLADQ8 molecules and covalently coupling the complex to 


\section{SEG-SEI-[HLA-DQ8] Collaboration in Anti-Tumor Response}

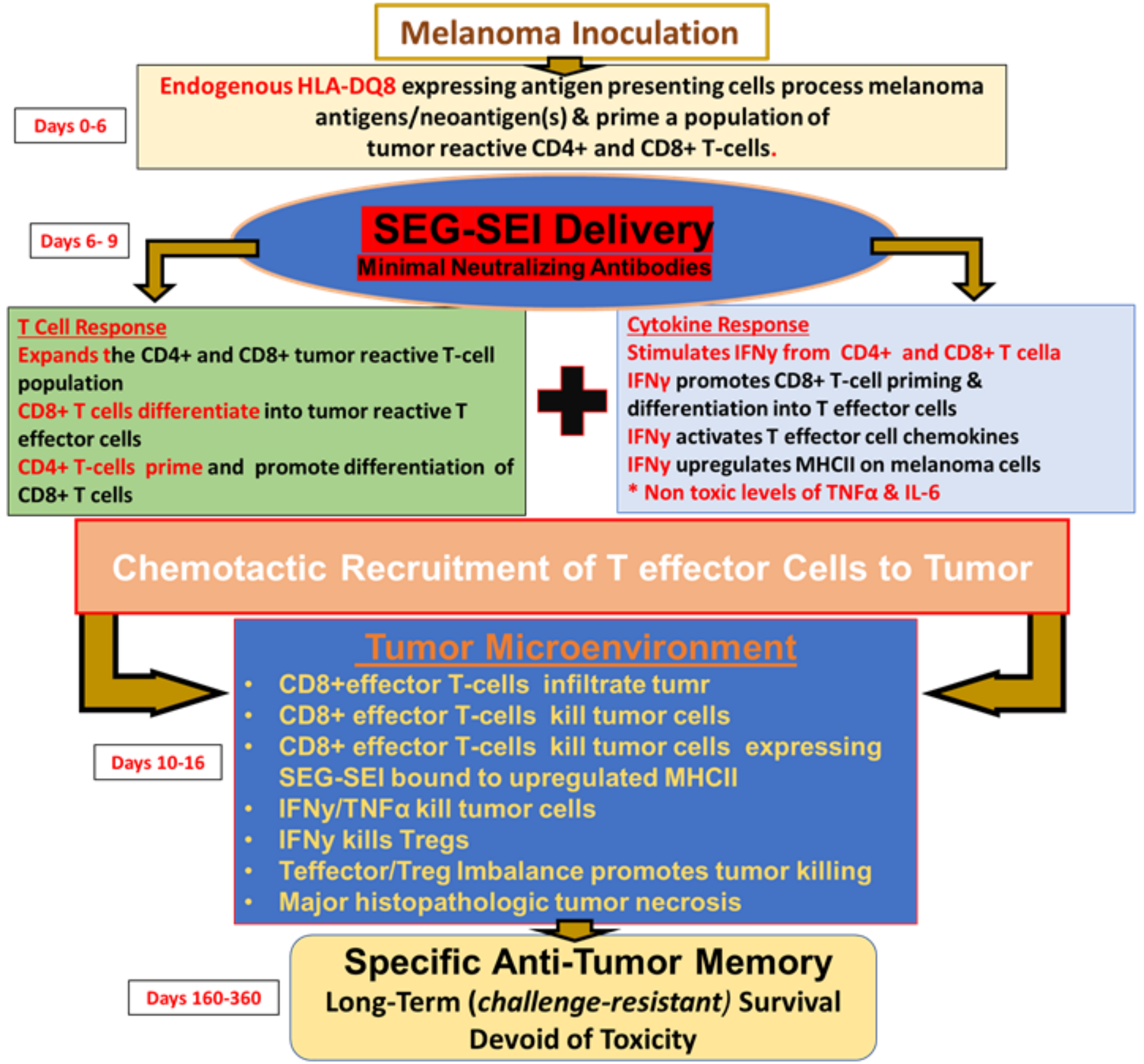

Figure 8 Antitumor effect and network induced by SEG/SEI in HLA-DQ8 tg mice resulting in long-term antitumor memory and melanoma survival is shown. Following melanoma inoculation on day $0, H L A-D Q 8$ expressing antigen presenting cells (APCs) recognize melanoma neoantigens and present them to T cells resulting in priming of tumor reactive CD4+ and CD8+T cells. This priming alone is insufficient to induce an anti-tumor response. Introduction of SEG/SEI on days 6 and 9, however, results in expansion of both CD4+ and CD8+Tcells. Following SEG/SEl treatment the primed CD4 +T cell population likely d promotes CD8 + T cell differentiation into T effector cells. The superantigenic $T$ cell activation also generates $T$ cell chemotactic molecules that enables recruitment of T effector cells to the tumor. SEG/SEl further initiates a surge of IFN $\gamma$ from both CD4 +and CD8+T cells. By days 13-16, the TME is infiltrated by CD8 +T effector cells along with IFN $\gamma$ and TNF $\alpha$ that appear to constitute the major tumoricidal effectors. CD8 $+\mathrm{T}$ effector cell tumor killing is likely enhanced by the relative paucity of Tregs and myeloid cells in the TME. Long-term surviving SEG/SEI-treated mice exhibit specific anti-tumor memory by resisting late challenge with melanoma cells while succumbing to inoculation with Lewis lung carcinoma. The long-term antitumor response suggests a self-sustaining feed forward mechanism possibly mediated by persistence of SEl in vivo in a high affinity, $\mathrm{Zn}^{++}$ dependent interaction with the HLA-DQ8 allele. IFN $\gamma$, interferon- $\gamma$; IL-6, interleukin 6; TNF $\alpha$, tumor necrosis factor- $\alpha$.

the surface of nanoparticles. Such SEG/SEI-HLA-DQ8 loaded nanoparticles may then be administered to the host. Strong binding affinities of SEG and SEI to MHCII should minimize their dissociation in plasma and absence of neutralizing antibodies against SEG/SEI in human sera should enable them to target thost TCRs. ${ }^{24}{ }^{25}$ Highly 
developed cationic liposomes, T cell targeted and MHCII derivatized nanoparticles loaded with biologics or tumor neopeptides have already been shown to activate $\mathrm{T}$ cells in vivo and initiate therapeutic responses in autoimmune disease or melanoma bearing mice. ${ }^{37} 70$ t1 Likewise, dendritic cells and macrophages loaded with small amounts of SAgs have been shown to initiate robust $\mathrm{T}$ cell responses in wild type mice. ${ }^{72}{ }^{73}$ Using similar principles, the long-lived tumor specific protection exhibited by SEG/SEI in our vaccination studies has clear application to susceptible human populations.

Collectively, these findings unveil a hitherto unrecognized SEG/SEI-(HLA-DQ8) complex that activates, directs, and drives a tumoricidal network culminating in tumor specific memory and long-term tumor regression devoid of TNFo-mediated toxicity. SEG/SEI are also devoid of neutralizing antibodies in humans thereby surmounting an additional barrier to clinical application. These properties distinguish SEG/SEI from other SAgs used previously in human tumor immunotherapy. More broadly, consolidation of these powerful principles within the SEG/SEI-(HLA-DQ8) complex constitutes a conceptually new anti-tumor weapon with compelling translational potential.

\section{METHODS \\ Mice}

All research performed, including animal and tissue collection, was conducted in accordance with the Animal Welfare Act and with the approval of the University of North Dakota's Institutional Animal Care and Usage Committee g. Female HLA-DQ8 (DQA*0301/ DQB*0302) tg breeding pairs were a gift from Dr. Chella David (Mayo Clinic, Rochester, Minnesota, USA) and their generation was described previously. ${ }^{38}$ The HLA-DQ8 phenotype was expressed on high proportion of peripheral blood lymphocytes (PBL), spleen and lymph node cells. ${ }^{29}$ Breeding pairs of C57BL/6 mice were obtained from Jackson Laboratories (Bar Harbor, Maine, USA). Mice were bred and maintained in specific pathogen-free conditions within the Center for Biological Research at the University of North Dakota.

\section{Cells}

B16-F10 murine melanoma cells, LLC and 4T1 mammary carcinoma were obtained from American Type Culture Collection. All cells were maintained in complete Dulbecco's Modified Eagle's Medium (cDMEM) containing $10 \%$ heat inactivated fetal bovine serum (FBS) (Atlanta Biologicals) and $50 \mathrm{IU} / \mathrm{mL}$ Penicillin/Streptomycin (MP Biologicals) in T-75 flasks (CytoOne). Single cells were isolated from spleens and lymph nodes by passing organs through a $70 \mu \mathrm{m}$ strainer (Falcon) with a $5 \mathrm{~mL}$ syringe plunger. All cells were washed with HBSS, RBCs were lysed with ACK lysis buffer for $5 \mathrm{~min}$ at $37^{\circ} \mathrm{C}$ washed again with cDMEM and filtered through a $70 \mu \mathrm{m}$ strainer.

\section{Superantigens}

SEG and SEI, were produced in Escherichia coli M15 as His-tagged recombinant toxins and purified by affinity chromatography on a nickel affinity column as previously described. ${ }^{74}$ Protein purity was verified by sodium dodecyl sulfate-polyacrylamide gel electropheresis (SDS-PAGE) and TCR vBeta profiles established for each SE. ${ }^{74}$ LPS was removed from toxin solutions by affinity chromatography (Detoxi-GEL endotoxin Gel, Pierce Rockford, USA). The QCL-1000 Limulus amebocyte lysate assay (CambrexBioWhittaker, Walkersville, USA) showed that the endotoxin content of the recombinant SAg solutions was less than 0.005 units $/ \mathrm{mL}$. SEA and SEB were obtained from Toxin Technology (Sarasota, Florida, USA). All reagents were kept at either $4^{\circ} \mathrm{C}$ or $-20^{\circ} \mathrm{C}$ and subject to no more than two freeze-thaw cycles.

\section{Flow cytometry}

Cells were washed with Hanks balanced salt solution (HBSS), stained with Ghost Dye (TONBO) for viability, FC blocked (BioLegend) and stained for extracellular antigens. Cells were fixed and permeabilized using FoxP3 staining buffer kit (TONBO) for intracellular cytokine and transcription factor analysis. Fluorescence minus one (FMO) and single stained controls were used for gating and compensation. Gating strategies are indicated within each experiment. In general, doublets and cell debris were excluded, and only Ghost Dye negative cells were used for analysis. Samples were analyzed using a BD LSRII or Symphony A3 flow cytometer at the North Dakota Flow Cytometry and Cell Sorting Core. Data were analyzed using FlowJo software.

\section{Assessment of $\mathrm{T}$ cells}

Splenocytes were isolated by passing mouse spleens through a $70 \mu \mathrm{m}$ nylon strainer (Falcon) using the plunger from a $5 \mathrm{~mL}$ syringe. Cells were washed with HBSS (Gibco), lysed for $5 \mathrm{~min}$ in ACK lysis buffer and subsequently washed and resuspended in DMEM (Gibco) containing 10\% heat inactivated FBS (Atlanta Biologicals) and Pen/Strep (1000 IU) (cDMEM) for downstream analysis. $\mathrm{T}$ cell proliferation was evaluated using Cell Proliferation Dye eFluor 450 (eBiosciences) dye. Briefly, splenocytes were stained with proliferation dye after which, $2 \times 10^{5}$ cells/well were seeded in 96-well round-bottom tissue culture plates (Becton Dickinson) in cDMEM and stimulated with SAgs for 72 hours $\left(37^{\circ} \mathrm{C}\right.$, $5 \% \mathrm{CO}_{2}$ and humidity) in $200 \mu \mathrm{L}$ volume. Concanavlin A, (Sigma) $1 \mu \mathrm{g} / \mathrm{mL}$ was used as a conrol. After 3 days, cells were processed for flow cytometry by using FC Block (BioLegend) and stained with 1:1000 dilution of TONBO ghost dye for $15 \mathrm{~min}$. Cells were then washed with HBSS containing 2\% FBS and stained for surface expression with 1:200 dilution of antibodies against CD3(17A2), CD4(RM4-5) CD8(53-6.7) and anti-CD127 (SB/199) (BioLegend) for 1 hour at $37^{\circ} \mathrm{C}$. For detection of intracellular perforin (S16009A), granzyme B(QA16A02) and IFN $\gamma(\mathrm{XMG1.2)}$ (BioLegend) and FoxP3 (MF23) 
(TONBO), cells were fixed and permeabilized using Foxp3 staining buffer kit (TONBO) then stained for 1 hour at $37^{\circ} \mathrm{C}$. FMO and single stained controls were used for gating and compensation.

\section{Assessment of tumor cells}

Tumors were isolated, rinsed with HBSS, minced with scissors and placed in $3 \mathrm{~mL}$ digestion solution containing $100 \mathrm{mg} / \mathrm{mL}$ type IV collagenase (Sigma) and $2000 \mathrm{IU} /$ $\mathrm{mL}$ type IV DNase (Sigma) in DMEM (Gibco) for 1 hour $\left(37^{\circ} \mathrm{C}, 5 \% \mathrm{CO}_{2}\right.$ and humidity) on a plate rocker. Tumor digests were passed through a $70 \mu \mathrm{m}$ nylon strainer (Falcon) and cells were washed with HBSS (Gibco) and RBCs lysed for 5 min in ACK lysis buffer. Tumor cells were blocked using FC Block (BioLegend) and stained with 1:1000 dilution of TONBO ghost dye for $15 \mathrm{~min}$. Cells were then washed with HBSS containing 2\% FBS and stained with 1:200 dilution of antibodies against CD45(30-F11), CD3(17A2), CD4(RM4-5), CD8(53-6.7), CD44(IM7), CD62L(MEL-14), CD25(PC61), CD11b(M1/70), Gr-1(RB6-8C5) (TONBO and BioLegend) for 1 hour at $37^{\circ} \mathrm{C}$. Cells were fixed and permeabilized using Foxp3 staining buffer kit (TONBO) then stained for 1 hour at $37^{\circ} \mathrm{C}$ for granzyme $\mathrm{B}$ (QA16A02), IFN $\gamma$ (XMG1.2) (BioLegend), FoxP3 (MF23) (TONBO). FMO and single stained controls were used for gating and compensation. Gating strategies are indicated within each experiment.

\section{Assays of cytokines and chemokines}

For measurement of cytokines in blood, samples were collected from the submandibular vein mice into EDTA tubes. Plasma cytokine concentrations were processed via flow cytometry and measured using LEGENDplex kit (BioLegend). For measurement of cytokines and chemokines in tumor tissue, tumors were weighed and lysed for 5 min using $2 \mathrm{~mm}$ stainless steel beads (Next Advance) and a Bullet Blender (Next Advance) in $300 \mu \mathrm{L}$ HBSS. Lysates were centrifuged for $5 \mathrm{~min}$ at $5000 \mathrm{x}$ g. Supernatants were subjected to one freeze thaw cycle and cytokines and chemokines were measured using a TH cytokine cytometric bead array (Biolegend). Results are reported as $(\mathrm{pg} / \mathrm{mL}) / \mathrm{mg}$ of tumor tissue.

\section{Mixed lymphocyte assays}

Mitomycin C-treated C57BL/6 splenocytes (red) were cocultured with splenocytes from HLA-DQ8 tg mice for 3 days at $37^{\circ} \mathrm{C}$ in $5 \% \mathrm{CO}_{2}$. $\mathrm{CD} 3+\mathrm{T}$ cell proliferation (green) was measured by dye dilution via flow cytometry and reported as per cent proliferation. SEB was used as a positive control for $\mathrm{T}$ cell proliferation

\section{In vivo tumor experiments}

In vivo tumor experiments were carried out using an established model of peritoneal and omental tumor metastases for evaluation of intracavitary therapeutics. ${ }^{76}$ In the vaccination model, mice were injected with $1 \times 10^{6}$ irradiated (15000 rads) B16-F10 melanoma cells intraperitoneally (ip) in $100 \mu \mathrm{L}$ HBSS (Life Technologies) on day -13 . On day -7 and day -3 , mice received $100 \mu \mathrm{L}$ injections ip of SEG and SEI (50 $\mu \mathrm{g}$ each). Mice were challenged on day 0 with $2.5 \times 10^{5}$ B16-F10 cells ip, evaluated daily and sacrificed when moribund. In the established tumor model, $2.5 \times 10^{5}$ B16-F10 melanoma cells were injected ip in $100 \mu \mathrm{L}$ PBS on day 0 . On days 6 and 9 post tumor inoculation, mice were injected with SEG and SEI $(50 \mu \mathrm{g}$ each) ip in $100 \mu \mathrm{L}$ of PBS. The same protocol was used to test the relative roles of $\mathrm{T}$ cell subsets in the antitumor response.,Individual groups of HLA-DQ8 tg mice were injected ip on days 2,4,7,9,12 with rat anti- CD4+ $(200 \mu \mathrm{g})$, rat anti-CD8+ $(500 \mu \mathrm{g})$ or isotype matched rat IgG $(300 \mu \mathrm{g})$ (BioXCell) in $100 \mu \mathrm{L}$ PBS. Mice were evaluated daily and sacrificed when moribund.

\section{Radiation}

Tumor cells were irradiated at 15000 rads using Gammacell 3000 (MDS Nordion, Canada).

\section{Histology and quantification of tumor density and necrosis}

Tumors were fixed with formalin and embedded in paraffin. Serial sections $5 \mu \mathrm{m}$ thick were cut floated onto charged glass slides (Super-Frost Plus, Thermo Fisher Scientific) and dried overnight at $60^{\circ} \mathrm{C}$. Sections were stained with H\&E. Slides were scanned at 1200 dpi and photographed as a TIFF image. The necrotic and viable areas of these sections were identified histologically with a Leitz Diaplan microscope and corroborated using Image J software. Necrotic tumor area was expressed as the percentage of pixels in the total tumor area minus the area of the viable tumor cells in the section. ${ }^{77}$ For determination of tumor density, all visible omental tumors were excised, and sections were stained, scanned, and photographed as TIFF images as described above. Tumor bearing areas were confirmed histologically and quantitated using the ImageJ software. Tumor density was expressed as total number of pixels in tumor bearing regions in each tumor section. Statistical analysis was based on a mean of 4 tumors per group.

\section{Data analysis}

One-way analysis of variance with Bonferroni's posttest and student's $\mathrm{t}$ test were performed where indicated. Kaplan-Meier curves and Mantel-Cox test were used to evaluate survival data. Statistical analysis was performed using GraphPad Prism software V.7.0a (La Jolla, California, USA).

Contributors Conceived of study: DT, DB; Designed the experiments: DT, DB, PK; Performed the investigations: PK, NR, TA, RL, DT; Analyzed the data: DT, DB, PK; Provided key materials: GL, CB, JB; Wrote the paper: DT; Edited the paper: DT, DB, PK.

Funding Supported by Center for Biomedical Research (NIH P20GM113123), the Dakota Cancer Collaborative on Translational Activity (DaCCoTA), CTR grant (NIH U54GM128729), the ND INBRE (NIH P20GM103442), Azore Cancer Imperative (non-profit).

Competing interests None declared.

Patient consent for publication Not required.

Ethics approval All research performed, including animal and tissue collection, was conducted in accordance with the Animal Welfare Act and with the approval 
of the University of North Dakota's Institutional Animal Care and Usage Committee g(IACUC).

Provenance and peer review Not commissioned; externally peer reviewed.

Data availability statement Data are available on reasonable request. All data from this study is available on request. Please contact DB at david.s.bradley@und. edu.

Supplemental material This content has been supplied by the author(s). It has not been vetted by BMJ Publishing Group Limited (BMJ) and may not have been peer-reviewed. Any opinions or recommendations discussed are solely those of the author(s) and are not endorsed by BMJ. BMJ disclaims all liability and responsibility arising from any reliance placed on the content. Where the content includes any translated material, BMJ does not warrant the accuracy and reliability of the translations (including but not limited to local regulations, clinical guidelines, terminology, drug names and drug dosages), and is not responsible for any error and/or omissions arising from translation and adaptation or otherwise.

Open access This is an open access article distributed in accordance with the Creative Commons Attribution Non Commercial (CC BY-NC 4.0) license, which permits others to distribute, remix, adapt, build upon this work non-commercially, and license their derivative works on different terms, provided the original work is properly cited, appropriate credit is given, any changes made indicated, and the use is non-commercial. See http://creativecommons.org/licenses/by-nc/4.0/.

\section{ORCID iD}

David Terman http://orcid.org/0000-0003-1384-4088

\section{REFERENCES}

1 Rosenberg SA, Restifo NP. Adoptive cell transfer as personalized immunotherapy for human cancer. Science 2015;348:62-8.

2 Sadelain M. Car therapy: the CD19 paradigm. J Clin Invest 2015; 125:3392-400.

3 Wei SC, Duffy CR, Allison JP. Fundamental mechanisms of immune checkpoint blockade therapy. Cancer Discov 2018;8:1069-86.

4 Langford MP, Stanton GJ, Johnson HM. Biological effects of sea on human peripheral lymphocytes. Infect Immun 1978;22:62-71.

5 Marrack P, Kappler J. The staphylococcal enterotoxins and their relatives. Science 1990;248:705-11.

6 Fraser JD, Proft T. The bacterial superantigen and superantigen-like proteins. Immunol Rev 2008;225:226-43.

7 Arad G, Levy R, Nasie I, et al. Binding of superantigen toxins into the CD28 homodimer interface is essential for induction of cytokine genes that mediate lethal shock. PLoS Biol 2011;9:e1001149.

8 Levy R, Rotfogel Z, Hillman D, et al. Superantigens hyperinduce inflammatory cytokines by enhancing the B7-2/CD28 costimulatory receptor interaction. Proc Natl Acad Sci U S A 2016;113:E6437-46.

9 Fraser JD. Clarifying the mechanism of superantigen toxicity. PLOS Biol 2011;9:e1001145.

10 Shu S, Krinock RA, Matsumura T, et al. Stimulation of tumor-draining lymph node cells with superantigenic staphylococcal toxins leads to the generation of tumor-specific effector T cells. J Immunol 1994;152:1277-88.

11 Coppola MA, Blackman MA. Bacterial superantigens reactivate antigen-specific CD8+ memory T cells. Int Immunol 1997;9:1393-403.

12 Torres BA, Perrin GQ, Mujtaba MG, et al. Superantigen enhancement of specific immunity: antibody production and signaling pathways. $J$ Immunol 2002;169:2907-14.

13 Meilleur CE, Wardell CM, Mele TS, et al. Bacterial superantigens expand and activate, rather than delete or incapacitate, preexisting antigen-specific memory CD8+ T cells. $J$ Infect Dis 2019;219:1307-17.

14 Terman DS, Serier A, Dauwalder O, et al. Staphylococcal entertotoxins of the enterotoxin gene cluster (egcSEs) induce nitrous oxide- and cytokine dependent tumor cell apoptosis in a broad pane of human tumor cells. Front Cell Infect Microbiol 2013;3:38-48.

15 Mollick JA, Chintagumpala M, Cook RG, et al. Staphylococcal exotoxin activation of T cells. Role of exotoxin-MHC class II binding affinity and class II isotype. J Immunol 1991;146:463-8.

16 Nooh MM, El-Gengehi N, Kansal R, et al. Hla transgenic mice provide evidence for a direct and dominant role of HLA class II variation in modulating the severity of streptococcal sepsis. J Immunol 2007;178:3076-83.

17 Kotb M, Norrby-Teglund A, McGeer A, et al. An immunogenetic and molecular basis for differences in outcomes of invasive group $A$ streptococcal infections. Nat Med 2002;8:1398-404.
18 Dohlsten M, Kalland T, Gunnarsson P, et al. Man-Made superantigens: tumor-selective agents for T-cell-based therapy. Adv Drug Deliv Rev 1998;31:131-42.

19 Patterson KG, Dixon Pittaro JL, Bastedo PS, et al. Control of established colon cancer xenografts using a novel humanized single chain antibody-streptococcal superantigen fusion protein targeting the 5T4 oncofetal antigen. PLoS One 2014;9:e95200.

20 Alpaugh RK, Schultz J, McAleer C, et al. Superantigen-targeted therapy: phase I escalating repeat dose trial of the fusion protein PNU-214565 in patients with advanced gastrointestinal malignancies. Clin Cancer Res 1998;4:1903-14.

21 Hawkins RE, Gore M, Shparyk Y, et al. A randomized phase II/III study of Naptumomab Estafenatox + IFN $\alpha$ versus IFN $\alpha$ in renal cell carcinoma: final analysis with baseline biomarker subgroup and trend analysis. Clin Cancer Res 2016;22:3172-81.

22 Cheng JD, Babb JS, Langer C, et al. Individualized patient dosing in phase I clinical trials: the role of escalation with overdose control in PNU-214936. J Clin Oncol 2004;22:602-9.

23 Jarraud S, Peyrat MA, Lim A, et al. Egc, a highly prevalent operon of enterotoxin gene, forms a putative nursery of superantigens in Staphylococcus aureus. J Immunol 2001;166:669-77.

24 Fernández MM, Cho S, De Marzi MC, et al. Crystal structure of staphylococcal enterotoxin G (SEG) in complex with a mouse T-cell receptor \{beta\} chain. J Biol Chem 2011;286:1189-95.

25 Fernández MM, Guan R, Swaminathan CP, et al. Crystal structure of staphylococcal enterotoxin I (SEI) in complex with a human major histocompatibility complex class II molecule. J Biol Chem 2006;281:25356-64.

26 Ferry T, Thomas D, Genestier A-L, et al. Comparative prevalence of superantigen genes in Staphylococcus aureus isolates causing sepsis with and without septic shock. Clin Infect Dis 2005;41:771-7.

27 Holtfreter S, Bauer K, Thomas D, et al. egc-Encoded superantigens from Staphylococcus aureus are neutralized by human sera much less efficiently than are classical staphylococcal enterotoxins or toxic shock syndrome toxin. Infect Immun 2004;72:4061-71.

28 Roetzer A, Gruener CS, Haller G, et al. Enterotoxin gene Clusterencoded sei and SEIN from Staphylococcus aureus isolates are crucial for the induction of human blood cell proliferation and pathogenicity in rabbits. Toxins 2016;8:314-22.

29 Mangalam A, Luckey D, Basal E, et al. HLA-DQ8 (DQB1*0302)restricted Th17 cells exacerbate experimental autoimmune encephalomyelitis in HLA-DR3-transgenic mice. J Immunol 2009;182:5131-9.

30 Welcher BC, Carra JH, DaSilva L, et al. Lethal shock induced by streptococcal pyrogenic exotoxin $A$ in mice transgenic for human leukocyte antigen-DQ8 and human CD4 receptors: implications for development of vaccines and therapeutics. $J$ Infect Dis 2002;186:501-10.

31 van Lummel M, van Veelen PA, Zaldumbide A, et al. Type 1 diabetesassociated HLA-DQ8 transdimer accommodates a unique peptide repertoire. J Biol Chem 2012;287:9514-24.

32 Busch R, De Riva A, Hadjinicolaou AV, et al. On the perils of poor editing: regulation of peptide loading by HLA-DQ and H2-A molecules associated with celiac disease and type 1 diabetes. Expert Rev Mol Med 2012;14:e15.

33 Maiers M, Gragert L, Klitz W. High-Resolution HLA alleles and haplotypes in the United States population. Hum Immunol 2007;68:779-88.

34 Marty Pyke R, Thompson WK, Salem RM, et al. Evolutionary pressure against $\mathrm{MHC}$ class II binding cancer mutations. Cell 2018; 175:416-28.

35 Linnemann C, van Buuren MM, Bies L, et al. High-throughput epitope discovery reveals frequent recognition of neo-antigens by CD4+ $T$ cells in human melanoma. Nat Med 2015;21:81-5.

36 Ott PA, Hu Z, Keskin DB, et al. An immunogenic personal neoantigen vaccine for patients with melanoma. Nature 2017;547:217-21.

37 Kreiter S, Vormehr M, van de Roemer N, et al. Mutant MHC class II epitopes drive therapeutic immune responses to cancer. Nature 2015;520:692-6.

38 Herman A, Croteau G, Sekaly RP, et al. Hla-Dr alleles differ in their ability to present staphylococcal enterotoxins to T cells. J Exp Med 1990;172:709-17.

39 Nabozny GH, Baisch JM, Cheng S, et al. Hla-Dq8 transgenic mice are highly susceptible to collagen-induced arthritis: a novel model for human polyarthritis. J Exp Med 1996;183:27-37.

40 Miethke T, Wahl C, Heeg K, et al. T cell-mediated lethal shock triggered in mice by the superantigen staphylococcal enterotoxin $\mathrm{B}$ : critical role of tumor necrosis factor. J Exp Med 1992;175:91-8.

41 Rajagopalan G, Polich G, Sen MM, et al. Evaluating the role of HLA$\mathrm{DQ}$ polymorphisms on immune response to bacterial superantigens using transgenic mice. Tissue Antigens 2008;71:135-45. 
42 Rajagopalan G, Sen MM, David CS. In vitro and in vivo evaluation of staphylococcal superantigen peptide antagonists. Infect Immun 2004;72:6733-7.

43 Tilahun AY, Karau M, Ballard A, et al. The impact of Staphylococcus aureus-associated molecular patterns on staphylococcal superantigen-induced toxic shock syndrome and pneumonia. Mediators Inflamm 2014;2014:1-13.

44 Castro F, Cardoso AP, Gonçalves RM, et al. Interferon-Gamma at the crossroads of tumor immune surveillance or evasion. Front Immunol 2018:9:847-60.

45 Dohlsten M, Sundstedt A, Björklund M, et al. Superantigen-Induced cytokines suppress growth of human colon-carcinoma cells. Int $J$ Cancer 1993:54:482-8.

46 Ferreyra GA, Elinoff JM, Demirkale CY, et al. Late multiple organ surge in interferon-regulated target genes characterizes staphylococcal enterotoxin B lethality. PLoS One 2014;9:e88756

47 Harlin H, Meng Y, Peterson AC, et al. Chemokine expression in melanoma metastases associated with CD8+ T-cell recruitment. Cancer Res 2009;69:3077-85.

48 Soler-Cardona A, Forsthuber A, Lipp K, et al. Cxcl5 facilitates melanoma cell-neutrophil interaction and lymph node metastasis. $J$ Invest Dermatol 2018;138:1627-35.

49 Sawant KV, Poluri KM, Dutta AK, et al. Chemokine CXCL1 mediated neutrophil recruitment: role of glycosaminoglycan interactions. Sci Rep 2016;6:33123.

50 Bischoff L, Alvarez S, Dai DL, et al. Cellular mechanisms of CCL22-mediated attenuation of autoimmune diabetes. J Immunol 2015;194:3054-64.

51 DeGrendele HC, Estess P, Siegelman MH. Requirement for CD44 in activated T cell extravasation into an inflammatory site. Science 1997;278:672-5.

52 Carlow DA, Gold MR, Ziltener HJ. Lymphocytes in the peritoneum home to the omentum and are activated by resident dendritic cells. $J$ Immunol 2009;183:1155-65.

53 Lhuillier C, Rudqvist N-P, Elemento O, et al. Radiation therapy and anti-tumor immunity: exposing immunogenic mutations to the immune system. Genome Med 2019;11:40.

54 Leone RD, Zhao L, Englert JM, et al. Glutamine blockade induces divergent metabolic programs to overcome tumor immune evasion. Science 2019;366:1013-21.

55 Bradley DS, Das P, Griffiths MM, et al. HLA-DQ6/8 double transgenic mice develop auricular chondritis following type II collagen immunization: a model for human relapsing polychondritis. $J$ Immunol 1998;161:5046-53.

56 Mangalam AK, Taneja V, David CS. Hla class II molecules influence susceptibility versus protection in inflammatory diseases by determining the cytokine profile. J Immunol 2013;190:513-9.

$57 \mathrm{Li} \mathrm{H}$, Llera A, Malchiodi EL, et al. The structural basis of T cell activation by superantigens. Annu Rev Immunol 1999;17:435-66.

58 Rajagopalan G, Smart MK, Marietta EV, et al. Staphylococcal enterotoxin $\mathrm{B}$-induced activation and concomitant resistance to cell death in CD28-deficient HLA-DQ8 transgenic mice. Int Immunol 2002:14:801-12.

59 Borst J, Ahrends T, Bąbała N, et al. CD4 ${ }^{+} \mathrm{T}$ cell help in cancer immunology and immunotherapy. Nat Rev Immunol 2018;18:635-47.

60 Alspach E, Lussier DM, Miceli AP, et al. MHC-II neoantigens shape tumour immunity and response to immunotherapy. Nature 2019:574:696-701.
61 Rizvi NA, Hellmann MD, Snyder A, et al. Cancer immunology. mutational landscape determines sensitivity to PD-1 blockade in non-small cell lung cancer. Science 2015;348:124-8.

62 Le DT, Durham JN, Smith KN, et al. Mismatch repair deficiency predicts response of solid tumors to PD-1 blockade. Science 2017;357:409-13.

63 Pauken KEet al. Epigenetic stability of exhausted T cells limits durability of reinvigoration by PD-1 blockade. Science (New York, N. Y.) 2016:354:1160-5

64 Dohlsten M, Lando PA, Björk P, et al. Immunotherapy of human colon cancer by antibody-targeted superantigens. Cancer Immunol Immunother 1995;41:162-8.

65 Chang J-H, Kim Y-J, Han S-H, et al. IFN-gamma-STAT1 signal regulates the differentiation of inducible Treg: potential role for ROSmediated apoptosis. Eur J Immunol 2009;39:1241-51.

66 Yarilina A, Park-Min K-H, Antoniv T, et al. Tnf activates an IRF1dependent autocrine loop leading to sustained expression of chemokines and STAT1-dependent type I interferon-response genes. Nat Immunol 2008;9:378-87.

67 Pless DD, Ruthel G, Reinke EK, et al. Persistence of zinc-binding bacterial superantigens at the surface of antigen-presenting cells contributes to the extreme potency of these superantigens as T-cell activators. Infect Immun 2005;73:5358-66.

68 Ren S, Terman DS, Bohach G, et al. Intrapleural staphylococca superantigen induces resolution of malignant pleural effusions and a survival benefit in non-small cell lung cancer. Chest 2004;126:1529-39.

69 Terman DS, Bohach G, Vandenesch F, et al. Staphylococcal superantigens of the enterotoxin gene cluster (egc) for treatment of stage IIIB non-small cell lung cancer with pleural effusion. Clin Chest Med 2006;27:321-34.

70 Clemente-Casares X, Blanco J, Ambalavanan P, et al. Expanding antigen-specific regulatory networks to treat autoimmunity. Nature 2016;530:434-40.

71 Schmid D, Park CG, Hartl CA, et al. T cell-targeting nanoparticles focus delivery of immunotherapy to improve antitumor immunity. Nat Commun 2017;8:1747-57

72 Bhardwaj N, Young JW, Nisanian AJ, et al. Small amounts of superantigen when presented on dendritic cells. are sufficient to initiate $T$ cell responses J Exp Med 1993;178:633-42.

73 Ganem MB, De Marzi MC, Fernández-Lynch MJ, et al. Uptake and intracellular trafficking of superantigens in dendritic cells. PLoS One 2013;8:e66244.

74 Thomas D, Dauwalder O, Brun V, et al. Staphylococcus aureus superantigens elicit redundant and extensive human Vbeta patterns. Infect Immun 2009;77:2043-50.

75 Seo KS, Park JY, Terman DS, et al. A quantitative real time PCR method to analyze $T$ cell receptor Vbeta subgroup expansion by staphylococcal superantigens. J Transl Med 2010;8:2.

76 Kominsky SL, Torres BA, Hobeika AC, et al. Superantigen enhanced protection against a weak tumor-specific melanoma antigen: implications for prophylactic vaccination against cancer. Int $\mathrm{J}$ Cancer 2001;94:834-41.

77 Kojima Y, Volkmer J-P, McKenna K, et al. CD47-blocking antibodies restore phagocytosis and prevent atherosclerosis. Nature 2016;536:86-90. 